\title{
Non-woody Biomass as Sources of Nanocellulose Particles: A Review of Extraction Procedures
}

\author{
Shesan J. Owonubi ${ }^{1 * t}$, Stephen C. Agwuncha ${ }^{2,3 t}$, Nyemaga M. Malima ${ }^{1,4}$, \\ Ginena B. Shombe ${ }^{1}$, Elizabeth M. Makhatha ${ }^{2}$ and Neerish Revaprasadu ${ }^{1}$ \\ ${ }^{1}$ Department of Chemistry, University of Zululand, KwaDlangezwa, South Africa, ${ }^{2}$ Department of Metallurgy, University \\ of Johannesburg, Johannesburg, South Africa, ${ }^{3}$ Department of Chemistry, Federal University Lokoja, Lokoja, Nigeria, \\ ${ }^{4}$ Department of Chemistry, University of Dodoma, Dodoma, Tanzania
}

Nanocellulose has been reported to be a very useful biomaterial with applications in biomedical, pharmaceutical, built industry, automobile, aerospace and many more.

OPEN ACCESS

Edited by:

Eldon R. Rene,

IHE Delft Institute for Water

Education, Netherlands

Reviewed by:

Arijit Dutta Gupta,

Motilal Nehru National Institute of Technology Allahabad, India

Quyet Van Le,

Duy Tan University, Vietnam Balendu Shekhar Giri,

Indian Institute of Toxicology

Research (CSIR), India

*Correspondence:

Shesan J. Owonubi

oshesan@gmail.com

†These authors have contributed equally to this work

Specialty section:

This article was submitted to

Bioenergy and Biofuels,

a section of the journal

Frontiers in Energy Research

Received: 21 September 2020 Accepted: 16 March 2021

Published: 08 April 2021

Citation:

Owonubi SJ, Agwuncha SC,

Malima NM, Shombe GB,

Makhatha EM and Revaprasadu N

(2021) Non-woody Biomass as

Sources of Nanocellulose Particles:

A Review of Extraction Procedures.

Front. Energy Res. 9:608825.

doi: 10.3389/fenrg.2021.608825
Its advantages over synthetic fibers include renewability, energy efficiency, cost effectiveness, biodegradability and good mechanical and thermal properties. However, the production of cellulose nanoparticles (CNPs) has focused more on woody plant sources. Non-woody biomass constitutes a large group of plant sources that are yet to be given the proper attention for utilization as raw material for nanocellulose particle production. This group of lignocellulosic biomasses is generally obtained as waste from farming activities, home gardens or office wastes. They are majorly composed of cellulose, hemicellulose, and lignin. However, their composition varies widely from one plant source to another. The variation in their composition results in limitations in the procedures employed in extraction of CNPs and of processing of the extracted CNPs. This means that different biomasses may have different ways by which CNPs are extracted from them. Therefore, this review intends to $x$-ray these variations, its effect on the structural properties of extracted CNPs and possible ways such limitations can be mitigated.

Keywords: TEMPO-mediated oxidation, alkalization, non-woody plants, acid hydrolysis, cellulose nanoparticles, extraction procedures

\section{INTRODUCTION}

Concerns over environmental safety and sustainability have pushed mankind into search for alternative materials to replace less environmentally friendly material. Synthetic polymers constitute nuisance to the environment because of their long half-life and inability to biodegrade in the environment. Additionally, landfills are rapidly being filled up with a forecasted problem of limiting the available land for other useful purposes. The drive for advanced and eco-friendly material for various applications in homes, offices and industries has propelled material scientists to the discovery of cellulose nanoparticles (Abdul Khalil et al., 2016). These cellulose nanoparticles (CNPs) have been found to possess superior physical, barrier, thermal and mechanical properties in comparison to other fibers extracted from the same sources (Salehpour et al., 2018; Sheikhi, 2019). CNPs are extracted majorly from plants by employing three major successive processes (Taha et al., 2016; Mishra et al., 2018; Salehpour et al., 2018; Agwuncha et al., 2019). These processes include alkalization or mercerization, bleaching and acid hydrolysis. Proper combination of these processes 
helps to remove all other components from the fiber, leaving behind highly crystalline nanocellulose particles (Lorenz et al., 2017; Salama et al., 2018; Agwuncha et al., 2020). The properties of the extracted CNPs are affected by the conditions utilized during each process, making it extremely important to select treatment conditions that will give the desired properties. The methods of extracting these nanocellulose are of great research interest around the world today, with various laboratories' scaledup investigations being reported in last decade (Sharma et al., 2019). Scale-up studies of industrial production of nanocellulose has also been reported with plants in the United States of America, Canada and Europe, although the first ever pilot plant was set up by Inventia, Sweden in 2011 (Phanthong et al., 2018). CNPs applications are very diverse and so are their properties. CNPs used for food packaging may possess extra quality not required in automobile industry and vice visa. To influence these properties, important modifications are made to the surface chemistry. Also, the matrix used in preparing biocomposites containing CNPs are important (Varanasi et al., 2015; Lei et al., 2018; Dacrory et al., 2019; Hivechi et al., 2019; Ramesh and Radhakrishnan, 2019).

The use of plant fibers predates the industrialization era. For over 40,000 years, the ancient civilization by the early humans utilized plant fibers to their advantage (Kvavadze et al., 2009). However, industrial revolution, which led to the discovery of steel and other alternative materials, including the production of synthetic polymers, led to the abandonment of these natural fibers. The industrial revolution made use of natural resources that are finite and cannot be renewed. The effect of environmental pollution has been felt more with increase in world population. The demand for more materials and energy resources has increased and so also is the generation of waste from homes, offices, and industries. The problem of replenishing these finite raw materials, managing these wastes generated and keeping the environment sane has now become a serious global issue (Rathore and Pradhan, 2017; Hamad et al., 2018). About three decades ago, material scientists went back in time to the use of plant fibers as a promising alternative. They identified that when these plant fibers are treated with alkaline solution, the mechanical and thermal properties were enhanced. In addition, the plant fibers upgraded the bulk properties of the composites when used in the preparation of composites (Balakrishnan et al., 2019; Shesan et al., 2019). Furthermore, the attractive properties of these plant fibers such as cost effectiveness, availability and renewable sources, encouraged the production of these biodegradable composites with little or no adverse effect on the environment (Johar et al., 2012; Sheikhi, 2019; Torgbo and Sukyai, 2019; Wang et al., 2019). Improvements in fiber treatment procedures led to the extraction of neat cellulose and further advancement has also encouraged the extraction of nanocellulose (see Figure 1). This work seeks to review the use of non-woody sources of lignocellulosic biomass especially those categorized as agro-waste to produce cellulose nanoparticles (CNPs). We intend to draw the attention of readers to their possible potentials and utilization. Furthermore, this work will also dwells on various factors that may limit or enhance the successful extraction of the CNPs from these sources.

\section{NON-WOODY LIGNOCELLULOSE BIOMASS AND THEIR SOURCES}

Non-woody plants are described as those plants with weak stems which can die back to the ground every year (see Figure 2). They are also known as herbaceous plants. In this review, nonwoody biomass sources will be described as all other sources of lignocellulosic biomass with exception to the woody plants. That is, lignocellulose biomass such as corn cob, corn husk, rice husk, stems of cereal plants, nutshells of plant fruits, agricultural wastes, garden wastes and grasses, and many more. According to Alila et al. (2013), the output of plants from crops and agricultural residues is huge and are receiving increasing attention. Thus, this group of biomass sources may constitute an important alternative for the extraction of cellulose in the nearest future. This is because the non-woody plants have shorter growth period; require moderate irrigation; have annual renewability, possess low lignin content and high annual yield of cellulose (Marques et al., 2010). The sources of this non-woody biomass are unending. Their usage is of no threat to any human activity, rather they bring about better and more sustainable environment. Agro-wastes or garden wastes, if not utilized, are mostly discarded by landfilling or by burning, which results in pollution. In recent times, nonwoody lignocellulose biomasses have been reportedly sourced from apple pomace (Melikoğlu et al., 2019), grape pomace (Coelho et al., 2018), passion fruit peels (Wijaya et al., 2017), sugarcane bagasse (Feng et al., 2018), kelp waste (Liu et al., 2017), elephant glass (Nascimento and Rezende, 2018), tea leaf (Abdul Rahman et al., 2017), banana fiber (Deepa et al., 2011), rice hull (Nascimento et al., 2016), groundnut shell (Bano and Negi, 2017), juncus plant stem (Kassab et al., 2020), and plum seed shell (Frone et al., 2017).

For over 50 years or more, CNPs extraction has been ongoing from biomass. However, it is only recently that the processes involved are better understood; encompassing simply harsh acid hydrolysis on plant material and then followed by ultrasonication. The utilization of agricultural wastes as feedstock by industries has been ongoing for a long time. It is a concept recognized as zero-waste where every by-product is converted to useful product(s). Agricultural waste had found many useful applications, among them are the use of agro-waste as organic manure; burnt to generate energy; used to fill gully for erosion control; and used as feeds for animals. In more recent times, lignocellulosic agro-wastes have been used to produce cellulose nanoparticles for different industrial applications (Missoum et al., 2014; Varanasi et al., 2015; Picheth et al., 2017; Abd El-Aziz et al., 2018; Lei et al., 2018; Singh et al., 2018; Hivechi et al., 2019; Indumathi et al., 2019; Ramesh and Radhakrishnan, 2019). Pistachio shell (Marett et al., 2017), blue agave waste (Robles et al., 2018), North African glass (Luzi et al., 2019), banana pseudo stem residue (Meng et al., 2019), groundnut shell (Bano and Negi, 2017), grape pomace (Coelho et al., 2018), shea nut shell (Agwuncha et al., 2020), rice husks (Nascimento et al., 2016; Ooi et al., 2016), corncob residue (Liu et al., 2016), passion fruit peels (Wijaya et al., 2017), fique fiber waste (OvalleSerrano et al., 2018), sugarcane bagasse (Oliveira et al., 2016), sago seed shells (Naduparambath and Purushothaman, 2016; 


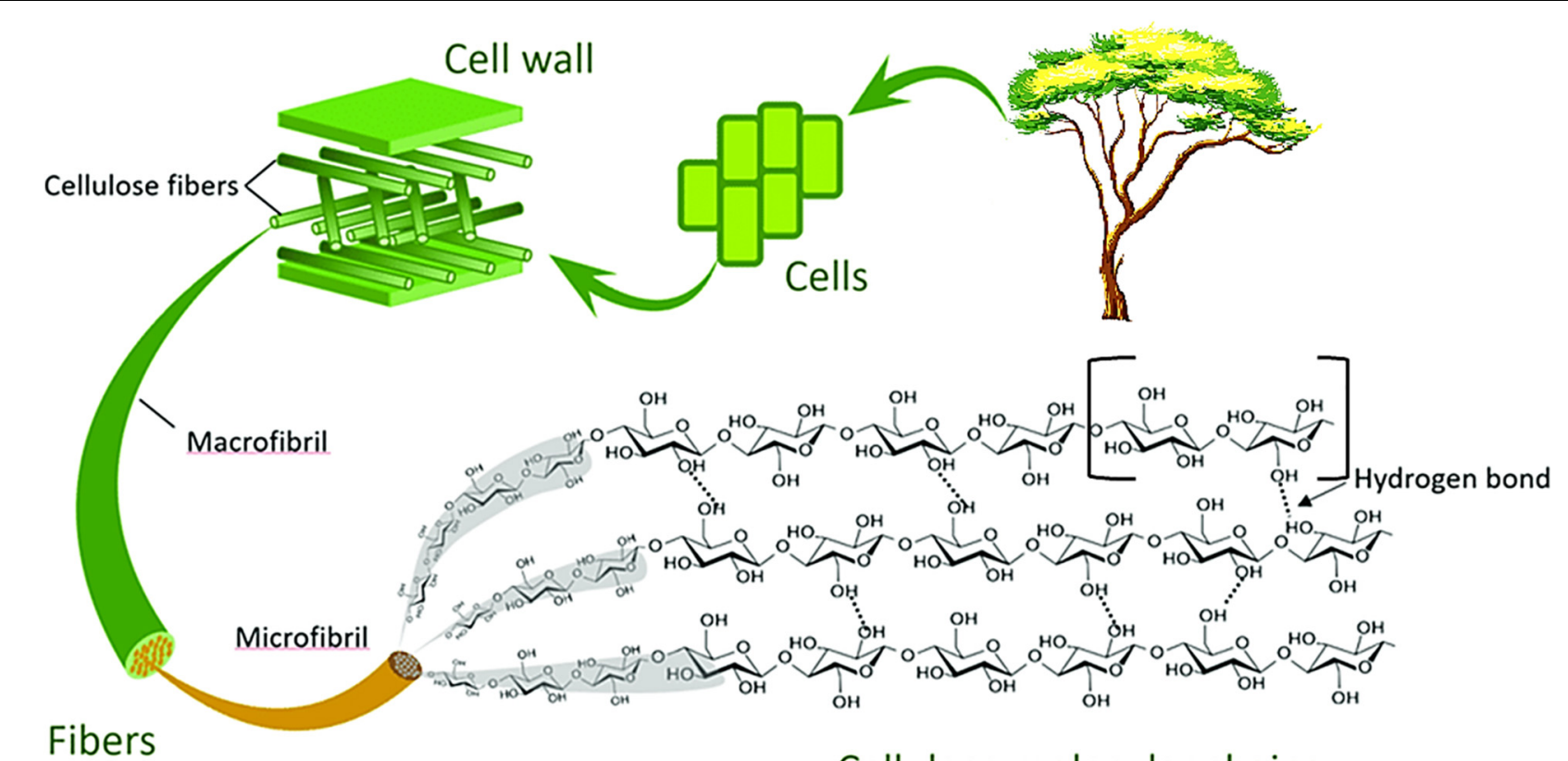

FIGURE 1 | A schematic showing the transition of plant fibers to cellulose nanoparticles.

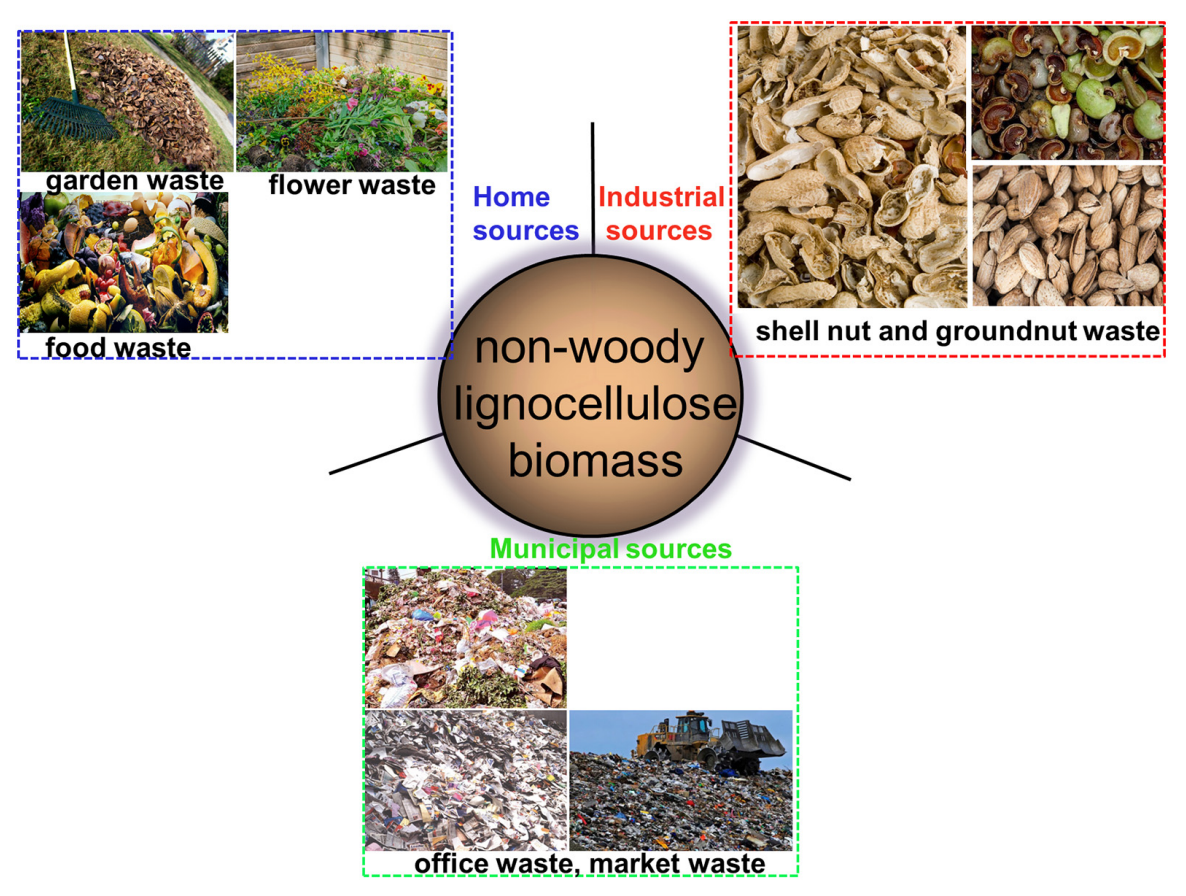

FIGURE 2 | Selected samples of non-woody lignocellulose biomass in our immediate environment.

Naduparambath et al., 2018), and many more. These wastes are from different parts of different plants, so it is expected that their chemical composition will vary widely. Plant fibers composition and properties have been reportedly linked to their type, origin and age (Bledzki, 1999). The vital constituents of plants fibers are cellulose, hemicelluloses and lignin. The eventual geometric dimensions and characteristic properties of CNPs are dependent directly on the source of cellulose, soil characteristics (water content), agronomic properties and cultivar factors, e.g., plant maturity and content of used fertilizers, (Luzi et al., 2014). Additionally, the process of preparation and potential post-treatment after the extraction can also affect the 
eventual CNPs properties (Fortunati et al., 2014; Luzi et al., 2014; Kargarzadeh et al., 2018).

\section{CHEMISTRY OF CELLULOSE TO NANOCELLULOSE}

Lignocellulosic biomasses are plants or plant based materials with various natural organic matters (Phanthong et al., 2018). They account for the leading quantity of sustainable carbon material and are also the most favorable source of raw material for sustainable production of biochemicals, bioethanol and biofuels (Lee et al., 2014). The structure of lignocellulose cell wall consists of three central biopolymers viz.: cellulose, lignin and hemicellulose (Modenbach and Nokes, 2014; Liu et al., 2016). A summary of the properties of these fiber components are presented in Table 1. According to literature, it is confirmed that the fibers chemical composition and structural assembly from lignocellulosic biomass dictates the extent of the modification (George et al., 2015). Table 2 presents the percentage composition of selected non-woody plant sources of lignocellulosic biomass for CNP extraction. The knowledge of the composition of the biomass can help to make informed decision about the conditions and parameters for isolation.

\section{Cellulose}

Cellulose is the key constituent of plant fiber, confined to the cell wall and comprises of linear homopolysaccharide of $\beta$-1,4- linked anhydro-D-glucose unit of cellobiose repeating units (Demirbaş, 2005; Burhenne et al., 2013; Li et al., 2015; Phanthong et al., 2018). Each repeating unit has three hydroxyl groups that form strong inter- and intra-hydrogen bonds with end-to-end glucose units, either on the same chain or a different chain. This leads to the formation of strongly packed crystalline cellulose fiber. These crystalline cellulose chains are tough with good strength, resistant to organic solvents and are insoluble in water. Different allomorphs of cellulose are formed because of the coordination of the hydrogen bonding networks and the molecules of glucose.

TABLE 1 | Summary of the properties of cellulose, hemicellulose and lignin from lignocellulose biomass.

\begin{tabular}{|c|c|c|}
\hline Cellulose & Hemicellulose & Lignin \\
\hline $\begin{array}{l}\text { Homogeneous } \\
\text { polysaccharide }\end{array}$ & $\begin{array}{l}\text { Heterogeneous } \\
\text { polysaccharides }\end{array}$ & $\begin{array}{l}\text { Heterogeneous aromatic } \\
\text { compounds }\end{array}$ \\
\hline $\begin{array}{l}\text { Most abundant in } \\
\text { nature }\end{array}$ & & $\begin{array}{l}\text { Second most abundant in } \\
\text { nature }\end{array}$ \\
\hline $\begin{array}{l}\text { Insoluble in water and } \\
\text { most organic solvents }\end{array}$ & $\begin{array}{l}\text { Hydrolyzed by dilute acid or } \\
\text { base. Not soluble in water }\end{array}$ & $\begin{array}{l}\text { insoluble in water but } \\
\text { soluble in acid/alkali }\end{array}$ \\
\hline $\begin{array}{l}\text { Semi crystalline with } \\
\text { high linearity }\end{array}$ & $\begin{array}{l}\text { Randomly amorphous and } \\
\text { branched }\end{array}$ & $\begin{array}{l}\text { Completely cross-linked } \\
\text { amorphous structure and } \\
\text { highly branched }\end{array}$ \\
\hline $\begin{array}{l}\text { Good mechanical and } \\
\text { thermal properties }\end{array}$ & $\begin{array}{l}\text { Poor thermal property and } \\
\text { weak mechanical property }\end{array}$ & $\begin{array}{l}\text { Poor thermal and } \\
\text { mechanical properties }\end{array}$ \\
\hline $\begin{array}{l}\text { Degree of } \\
\text { polymerization between } \\
5,000 \text { and } 15,000\end{array}$ & $\begin{array}{l}\text { Degree of polymerization } \\
\text { between } 200 \text { and } 3000\end{array}$ & $\begin{array}{l}\text { Degree of polymerization is } \\
\text { difficult to measure }\end{array}$ \\
\hline Highly linear & Branched in nature & Highly branched in nature \\
\hline
\end{tabular}

However, formation is dependent on the origin of fibers and the method of treatment given (Moon et al., 2011). Cellulose is the main structural component of plant cell responsible for the mechanical strength and its walls (Lu and Hsieh, 2010; Habibi, 2014).

\section{Hemicellulose}

Hemicellulose is another major component of lignocellulosic biomass. It is an amorphous polymer that is randomly assembled and structurally complex (Heredia et al., 1995; McKendry, 2002; Thielemans et al., 2009; Abdul Khalil et al., 2016). Hemicellulose helps to bind cellulose and lignin in the fiber. Therefore, it forms the link between the hydrophobic lignin and hydrophilic cellulose, providing the rigidity in plants. Chemically, hemicelluloses are heterogeneous and amorphous polysaccharides of low molecular weight compromising of glucomannans, mannans, xylans, and xyloglucaus. Hemicellulose demonstrates an amorphous structure, defined by repeated polymers of pentose and hexose units. Hemicellulose is characterized by branched multiple polysaccharide polymer (sugars: galactose, mannose, arabinose, glucose, and xylose) (Sheltami et al., 2012).

\section{Lignin}

Lignin is described as a complex, phenolic polymer acting as a protective barrier which encases the cellulose and hemicellulose (Buranov and Mazza, 2008). Lignin is an extremely crosslinked amorphous polymer that surrounds and protects celluloses and hemicelluloses (Sheltami et al., 2012). Lignin helps to give the plants its structural support.

\section{EXTRACTION PROCESSES AND PROCEDURES}

In the last decade, the number of published articles in the subject area of CNPs extraction, isolation, modification, characterization and application has increased tremendously (Bacakova et al., 2019). Many have reported similar procedures for obtaining CNP but ending up with different results (see Table 3), while some have had to alter reported procedures to achieve close to reported results. In all these, the challenges remain in getting a reliable method to follow or deciding what conditions are best for your new plant source or plant part for some younger scientists. This section seeks to review published reports, compare their common factors, and put together a scientific reason as reference for selecting an appropriate method or procedure for any CNP extraction.

According to reports, both hemicellulose and lignin are susceptible to chemical attacks. However, considering that cellulose is made up of regions that are amorphous and crystalline, the crystalline region is conserved by the presence of hydrogen bonds and Van der Waal forces. This prevents the penetration of chemicals solution making it less susceptible to chemical attacks. On the other hand, the amorphous regions consist of twisted chains which permit the penetration of the chemical solutions, hence their susceptibility to chemical 
TABLE 2 | Percentage composition of selected lignocellulose biomass and procedures use to obtain higher cellulose content.

\begin{tabular}{|c|c|c|c|c|c|c|c|c|c|}
\hline & \multirow[t]{2}{*}{ Lignocellulose biomass } & \multicolumn{2}{|c|}{ Cellulose (\%) } & \multirow[t]{2}{*}{ Hemicellulose (\%) } & \multirow[t]{2}{*}{ Lignin (\%) } & \multicolumn{3}{|c|}{ Pretreatment carried out } & \multirow[t]{2}{*}{ References } \\
\hline & & B & A & & & Dewaxing & Alkaline & Bleaching & \\
\hline 1 & Passion fruit peel & 29 & 80 & 23 & 36 & No & Yes & yes & Wijaya et al., 2017 \\
\hline 2 & Wood & 46 & 80 & 27 & 25 & yes & yes & yes & Chen et al., 2011 \\
\hline 3 & Bamboo & 42 & 84 & 27 & 23 & Yes & Yes & Yes & \\
\hline 4 & Wheat straw & 40 & 84 & 34 & 20 & Yes & Yes & Yes & \\
\hline 5 & Flax & 75 & 89 & 13 & 3 & Yes & Yes & Yes & \\
\hline 6 & Grape pomace & 19 & 80 & 7 & 16 & Yes & Yes & Yes & Coelho et al., 2018 \\
\hline 7 & Groundnut shell & 38.31 & 83 & 28 & 21 & Yes & Yes & Yes & Bano and Negi, 2017 \\
\hline 8 & Sugarcane bagasse & 45.0 & 87 & 30 & 21 & Yes & No & yes & Oliveira et al., 2016 \\
\hline 9 & Tea leaf & 16.2 & 83 & 68.2 & 19 & No & Yes & Yes & Abdul Rahman et al., 2017 \\
\hline 10 & Hemp & 70.6 & - & 15.6 & 4 & Yes & Yes & Yes & Mondragon et al., 2014 \\
\hline 11 & Sisal & 62.6 & - & 12.5 & 8 & Yes & Yes & Yes & \\
\hline 12 & Flax & 66 & - & 18 & 2 & yes & yes & yes & \\
\hline 13 & Bagasse & 72 & - & 16 & $<1$ & No & No & Yes & Zhang et al., 2016 \\
\hline 14 & Banana fiber & 64 & 96 & 19 & 5 & no & yes & yes & Deepa et al., 2011 \\
\hline 15 & Coconut & 35 & 65 & 25 & 36 & Yes & Yes & yes & Nascimento et al., 2014 \\
\hline 16 & Jackfruit peel & 20 & - & 24 & 2 & Yes & Yes & Yes & Trilokesh and Uppuluri, 2019 \\
\hline 17 & Soy hull & 48 & - & 24 & 6 & No & Yes & Yes & Flauzino Neto et al., 2013 \\
\hline 18 & Alfa fiber & 46 & 87 & 26 & - & No & Yes & Yes & El Achaby et al., 2018b \\
\hline 19 & Sugar palm fiber & 44 & 82 & 7 & 33 & yes & yes & yes & Ilyas et al., 2018 \\
\hline 20 & Pineapple leaf & 81 & 99 & 12 & 3 & no & yes & yes & Cherian et al., 2010 \\
\hline 21 & Banana stem & 24 & 93 & 26 & - & yes & no & yes & Meng et al., 2019 \\
\hline 22 & Fique tow fiber & 52 & 83 & 24 & 24 & yes & no & yes & Liu et al., 2017 \\
\hline
\end{tabular}

attacks, leaving the crystalline regions unchanged. Thus, it is the chopping off of the amorphous region (depolymerization), either by chemical cleavage or mechanical rupturing that results in cellulose nanoparticles formation (Lee et al., 2014; Abdul Khalil et al., 2016). The mechanical and/or chemical treatments are able to breakdown the amorphous cellulose and at the same time destroy lignin and hemicellulose (Rampazzo et al., 2017). The size, shape and applications of the CNPs obtained greatly depend on the kind of treatments and the conditions given to the fibers (Ng et al., 2015; Shesan et al., 2019,a,b).

\section{Processes and Procedures}

In the preparation of CNPs, researchers have reported different procedures and processes. In a review (Abdul Khalil et al., 2016), the authors classified the entire processes into two major stages: (i) pretreatment, which includes cleaning of the fibers, removal of extractives, pulping or alkaline treatment and bleaching, and (ii) CNPs production involving depolymerization and mechanical isolation of the prepared CNPs. The problem with this classification is that it has muddled up important procedures together and this may trivialize their importance in the production processes. The actual production of CNP usually occurs during the depolymerization process. However, the efficiency of the depolymerization process is predicated on good and efficient removal of all other non-cellulosic components during the pre-treatment stages. Therefore, as a form of guide, the extraction of CNPs may follow these under listed steps:

\author{
i Dewaxing of the fiber \\ ii Mercerization or alkalization \\ iii Bleaching \\ iv Acid hydrolysis or depolymerization \\ $\mathrm{v}$ Isolation
}

These steps greatly depend on the kind and source of fibers used. This also underscores the importance of carrying out compositional analysis of the fiber to be used prior to extraction. For example, cotton may not require the cleaning step considering that it contains very low content of extractives, such as wax, oil and pectin. While protein-like plant shells such as cashew nut, sago seed shell or shea nut shells will require all the steps (Naduparambath et al., 2018; Agwuncha et al., 2020). Figure 3 presents a pictorial overview of the steps involved. However, the following sub-sections will focus on the chemistry of each step listed.

\section{Dewaxing of Fibers}

This dewaxing step involves the removal of minor components which are referred to as extractives. These extractives include components such as wax, phenolics, pigments and oil (Coelho et al., 2018). The dewaxing process is achieved by using a mixture of organic solvents with varying polarity. For example, benzene and methanol (Bano and Negi, 2017), hexane and ethanol (Lee et al., 2017), ethanol and toluene (Mondragon et al., 2014; Marett et al., 2017; Luzi et al., 2019), benzene and ethanol (Chen et al., 2011). The extractives are within the range of non-polar to polar, 
TABLE 3 | Processing conditions for the extraction of nanocellulose from selected literatures.

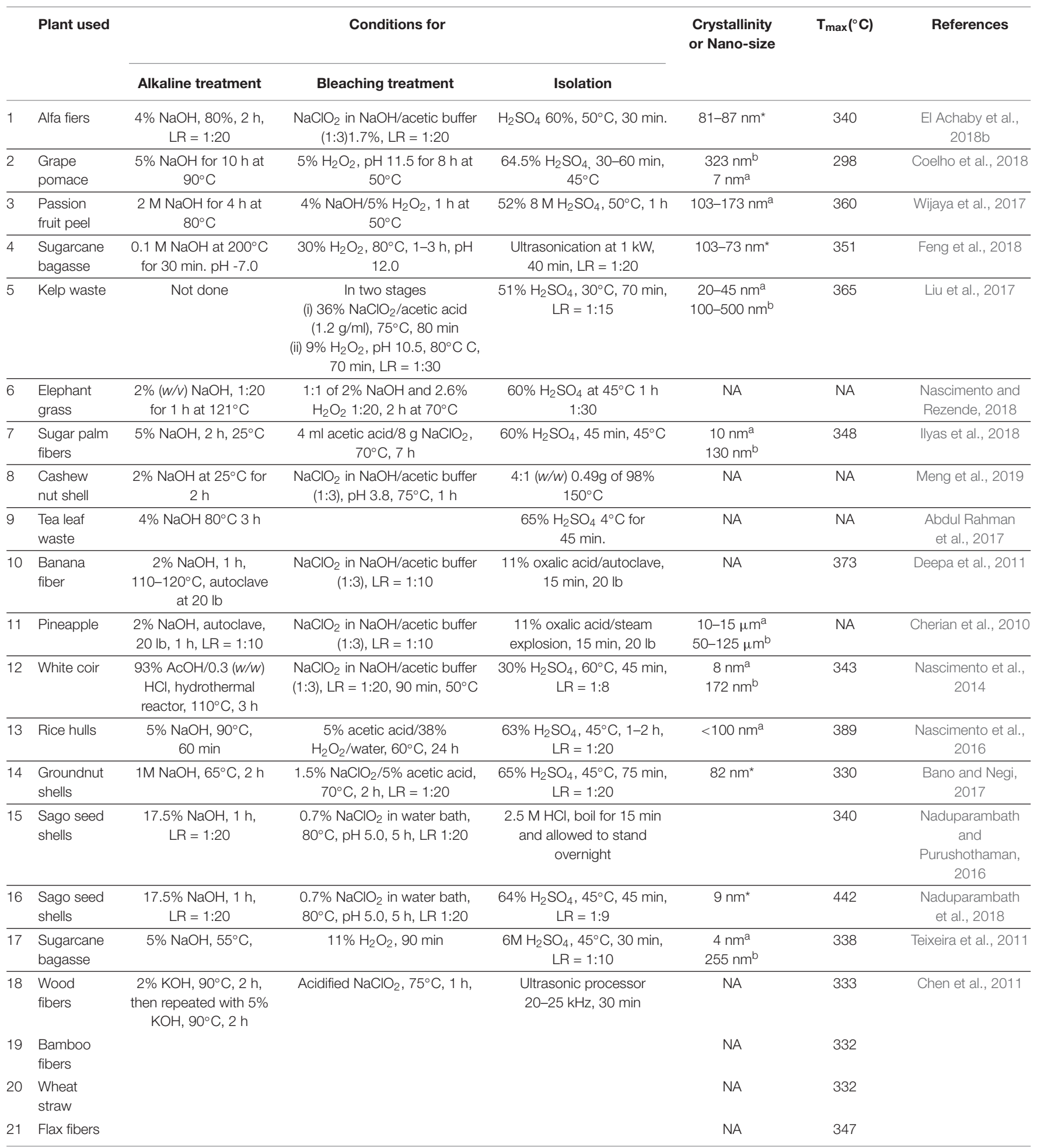

${ }^{a}$ and ${ }^{b}$ for the width and length of the nanoparticles, respectively.

* data presented as average of the nanoparticle sizes.

therefore they can interact with at least one of the solvents in the mixture. Also, elevating the dewaxing temperature can increase the efficiency of the process.
Recently, many research groups have employed pre-treatment for eliminating non-cellulosic materials from agriculture biomasses in order to improve the effectiveness of the other steps 


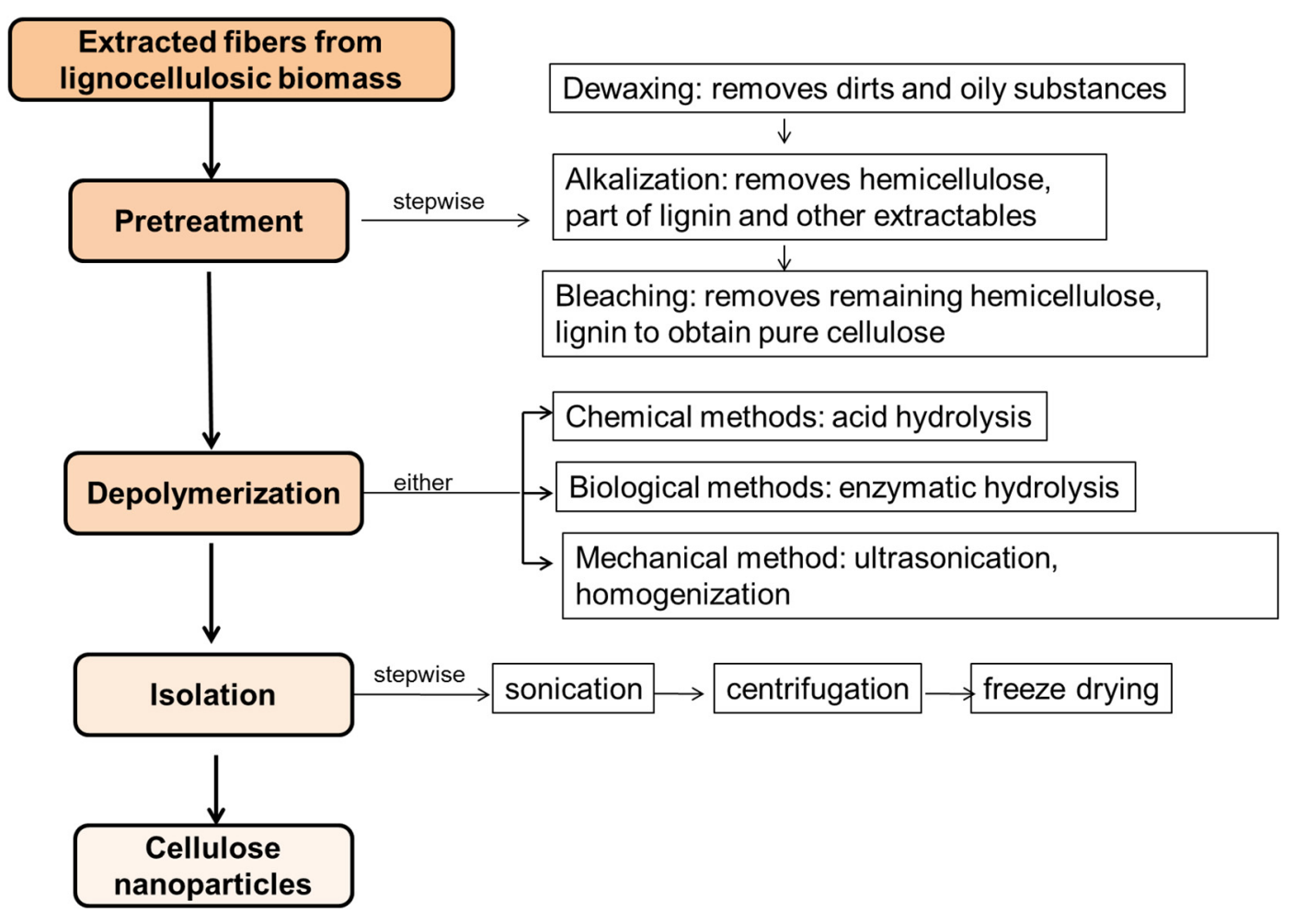

FIGURE 3 | Schematic showing the chemical processes involved in the extraction of nanocellulose starting with untreated fibers.

(Phanthong et al., 2018). For instance, researchers investigated the effect of pre-treatment of rice husks with alkaline solution followed by a bleaching process (Johar et al., 2012). They established that the content of cellulose in the untreated rice husks increased from 35-96 wt\% in the final products after bleaching and alkaline pre-treatments. It is of importance to mention that Johar and colleagues did not detect hemicellulose, lignin and other non-cellulosic materials in these final products. Other agricultural wastes such as sugarcane bagasse (Li et al., 2012), oil palm empty fruit bunch (Haafiz et al., 2013, 2014), pineapple leaf (Santos et al., 2013), apple stem (Phanthong et al., 2015), coir fiber (Abraham et al., 2013), mulberry bark (Li et al., 2009), rice hulls, bean hulls (Adel et al., 2010) and cotton linters (Morais et al., 2013) were also reportedly pretreated before nanocellulose extraction and the results obtained showed that the percentage cellulose and CNP obtained afterward were greatly improved.

The dewaxing process can be followed by the treatment of the fiber with very diluted alkaline solution ( $1 \mathrm{wt} \%)$ at elevated temperature. This additional step is regarded as pre-alkalization; it helps to swell the fiber for the eventual alkaline treatment step. This can be done using potassium hydroxide $(\mathrm{KOH})$ or sodium hydroxide $(\mathrm{NaOH})$ solution at a temperature of $40-50^{\circ} \mathrm{C}$ for about $12 \mathrm{~h}$, thereby improving the penetration rate during alkalization. Many reported findings showed that quite a number of researchers do not carry out dewaxing and pre-alkalization processes. This may be attributed to mostly the additional cost to the research. For non-woody fiber sources like leaves, husks, shells, grasses to mention a few, the dewaxing may be very useful
(Table 1). For samples with very low cellulose content, dilute acid can be used as substitute for the pre-alkalization step. For example, some researchers have reportedly employed $2 \%$ sulfuric acid $\left(\mathrm{H}_{2} \mathrm{SO}_{4}\right)$ solution to pretreat samples of grape pomace with initial cellulose content of $19.3 \%$ at $90^{\circ} \mathrm{C}$ for $5 \mathrm{~h}$ to allow for the hydrolysis of all acid-soluble polyphenolics and polysaccharides (Coelho et al., 2018).

\section{Alkalization}

This is the process of treating the fibers with concentrated solution of alkali to remove hemicellulose and some percentage of lignin. $\mathrm{NaOH}$ or $\mathrm{KOH}$ are commonly used for this process and are done at high temperatures between 70 and $160^{\circ} \mathrm{C}$, dependent on the concentration of the alkali solution being used, which can be within the range of 4-20 wt\% (Mondragon et al., 2014; Luzi et al., 2019). As indicated previously, the crystalline region of the cellulose content is compact and restricts penetration of the alkali solution. Hence, the reaction of cellulose with the alkali is at the surface only (i.e., a surface phenomenon) and at the amorphous region too (Kargarzadeh et al., 2017). The pre-alkalization step will help increase penetration of this alkali solution by increasing access to more surfaces for greater interaction. The more surfaces the alkali can access, the more interaction there will be and this will result in more nanosized CNPs obtained (Ng et al., 2015). Hemicellulose is highly susceptible to alkaline treatment (Modenbach and Nokes, 2014). The reaction point of hemicellulose during alkaline treatment has been reported to be the ferulic acid linkage that connects the hemicellulose and lignin (Buranov and Mazza, 2008). 
Bruice reportedly indicated that, the extent of the reaction greatly depends on the concentration of the alkaline solution (Bruice, 2003). The ester bond between the carbohydrate and the ferulic acid is vastly vulnerable to degradation by alkali. Bruice established that as the hydroxyl ion from $\mathrm{NaOH}$ increases, the rate at which the hydrolysis reaction occurs in comparison to water also increases (Bruice, 2003). The mechanism of alkaline pretreatment was described by researchers (Modenbach and Nokes, 2014). They indicated that the hydroxyl ion attacks the carbon of the ester bond, between the carbohydrate and lignin or in some instances amongst two lignins or two carbohydrates. This leads to the formation of a tetrahedral intermediate, which rapidly falls apart when an oxygen atom that is negatively charged substitutes an alkoxide $\left(-\mathrm{OCH}_{3}\right)$ from the carboxylic acid (Modenbach and Nokes, 2014). It is a rapid reaction and the resultant alkoxide performs as a base, deprotonating the carboxylic acid. The outcome is the permanent hydrolysis of the ester bond, eroding the structural integrity of the lignocellulose. Therefore, the timing must be right.

The choice of alkali treatment condition depends on (i) the source of fibers and (ii) to a lesser degree, the morphology desired of the cellulose prior to further treatments. It is noteworthy to mention that suitable pretreatment of cellulose fibers encourages accessibility to the cellulose, breaks hydrogen bonds, alters crystallinity, increases the inner surface and boosts the reactivity of the cellulose; thus, it reduces the need for energy and eases the eventual nanocellulose (NC) production process (Šturcová et al., 2005; Abdul Khalil et al., 2014). For instance, plant materials pretreatment encourages the thorough or partial removal of non-cellulose constituents (lignin, hemicellulose, etc.), and the seclusion of singular fibers (Peng et al., 2011). At this stage, lignin is partially solubilized, and some percentage will also be removed. The concentration of the alkaline solution used (i.e., the eventual ratio of fiber to alkali solution) is important. This is because water aids the reaction, increases the lubricity of the particles, and lessens the viscosity of the mixture, providing a mass transfer medium, through diffusion of the alkaline solution into the fiber, thereby enhancing the removal of hemicellulose at this stage.

\section{Bleaching}

At the bleaching stage, the lignin is completely removed. It is sometimes referred to as delignification. The bleaching of lignicellulose biomass has been carried out using different combinations of chemicals at different conditions too. Common amongst them are sodium chlorite with acetate buffer (Abdul Rahman et al., 2017), hydrogen peroxide with $\mathrm{NaOH}$ maintained at pH 11.5 (Ovalle-Serrano et al., 2018), hydrogen peroxide in acetic acid and water in ratio (38:50:72, v/v) (Nascimento et al., 2016). Plant fibers treatment to remove lignin can be done before or after alkalization. This is because the removal of lignin does not depend on the presence or absence of hemicellulose. However, if done after alkalization, it is easier to tell a more complete removal by the color of the cellulose obtained.

The bleaching and alkalization processes can be affected by the amount of water molecules existing in the reaction vessel; hence the ratio of biomass to reagent volume is very important. Also, the concentration, duration and temperature of treatment are equally vital and depend greatly on the kind of reagent used for the bleaching process.

\section{Depolymerization of Cellulose}

As earlier mentioned, the depolymerization of cellulose chains is the stage where the nanoparticles of cellulose are fashioned. It involves the chemical cleavage of the cellulose chain at the amorphous region to produce cellulose nanocrystals or the mechanical splitting/separation of the cellulose chains at the crystalline region to produce cellulose nanofibers. These are the two major types of cellulose nanoparticles known and are well defined and described by Agwuncha et al. (2019). However, discussion here will focus more on the chemicals used to generate CNPs; either using the chemical or mechanical methods.

The chemical treatment used in the isolation of CNPs involves the use of strong acid to attack and break the chains in the amorphous regions or the use of strong oxidizing agents to attack the chains to achieve the same result. More universally used reagents are hydrochloric acid, sulfuric acid, formic acid; phosphoric acid and nitric acid (see Table 3). On the other hand, a mixture of 2, 2, 6, 6-tetramethylpiperidin-1-oxyl or 2, 2, 6, 6-tetramethyl piperidin-1-oxidany and sodium bromide (TEMPO/NaBr) in an acidic medium is used for oxidizing the $\mathrm{OH}$ groups (Meng et al., 2019). Amongst the acids listed for hydrolysis, sulfuric acid is the most preferred because it forms a stable colloid in water. Reports have shown that different researchers using sulfuric acid have done so with varying reaction parameters and conditions as shown in Table 3, even when using the same biomass samples (Liu et al., 2016; Oliveira et al., 2016; Robles et al., 2018; Luzi et al., 2019). The concentration of the acid used typically varies (30-65\%), the time of treatment (35$60 \mathrm{~min})$ and the temperature of treatment varies $\left(35-65^{\circ} \mathrm{C}\right)$. These variations are as a result of property variations of the cellulose samples used (Kargarzadeh et al., 2017).

\section{Acid Hydrolysis}

Acid hydrolysis under controlled conditions encourages the elimination of the amorphous region of the cellulose fibers while leaving the crystalline domains undamaged in the form of crystalline nanoparticles. This elimination influences the surface morphology, crystallinity, thermal stability, as well as the structure of fibers (Ilyas et al., 2017, 2018). The control of the duration of acid hydrolysis is quite delicate; reason being that the crystallinity of CNC is proportional to the treatment time, whilst the aspect ratio is reciprocal to the hydrolysis time due to the reduction of non-crystalline amorphous regions.

Control and careful study of the hydrolysis conditions allow for the synthesis of materials with the desired morphology (Tee et al., 2013). CNCs have been obtained using concentrated sulfuric acid, at varying reaction times and temperatures. The process operating conditions have been established experimentally on diverse cellulosic materials. In most cases, the concentration of acid solution utilized in treating the cellulose fibers is around $30-65 \mathrm{wt} \%$ in water, the ratio of fibers to acid solution is $10-20 \mathrm{ml}$ per gram of "purified" cellulose. The hydrolysis time can vary from $20 \mathrm{~min}-4 \mathrm{~h}$ dependent on the reaction temperature which ranges $\left(30-105^{\circ} \mathrm{C}\right.$ ) (Rosa et al., 2010; 
Rebouillat and Pla, 2013). For instance, in conditions of lower acid concentration and lower temperature, the time consumed for the hydrolysis tends to be longer in order to make up for the inadequate reaction during hydrolysis (Kargarzadeh et al., 2012).

\section{Enzymatic Hydrolysis}

Another form of hydrolysis employed by researchers is enzymatic hydrolysis which takes advantage of biological processes that utilizes enzymes for cellulose fibers modification or digestion to acquire much purer cellulose. Commonly used enzymes reported for this purpose are cellulases, endoglucanases, cellobiohydrolases etc. Although it is a complex mechanism, the enzymatic action is based on catalysis/breaking of hydrogen bonds linking cellulose microfibers.

The enzymatic hydrolysis is sometimes combined with other processes to address the issue of complex mechanism. For instance, researchers have reported cellulose fibers treatment using ionic liquid prior to enzymatic hydrolysis which made use of laccase for isolation of nanocellulose from wood chips (Moniruzzaman and Ono, 2013). They reportedly obtained nanocellulose possessing improved surface area with higher thermal stability and crystallinity in comparison to others published for obtaining nanocellulose from native wood source. However, due to time and cost involved, researchers may prefer the use of acid hydrolysis.

\section{Isolation}

Cellulose fibers have been mechanically treated to sequester nanocellulosic fibers using various mechanical methods such as ultra-sonication, high pressure homogenization and ball milling (Klemm et al., 2011; Phanthong et al., 2018). However, the foremost drawback of these processes is that they required high energy input; hence the need for incorporation of initial pretreatment procedures to reduce such energy requirement.

The use of TEMPO mediated oxidation for the delamination of the cellulose fibers to produce cellulose nanofibers (CNF) is receiving increased attention (Lee et al., 2018). Before now, mechanical treatment methods have been employed to pulverize the biomass samples into micrometer-scale particles. This increases the efficiency of the swelling, improves purification and separation into individual fibrils (Moon et al., 2011; Dufresne, 2013; Lee et al., 2018). The mechanical methods which are energy consuming include high-intensity ultrasonication, highshear homogenization, grinding and cryocrushing. However, the use of TEMPO mediated oxidation process helps to reduce and in some cases, eliminate the high energy requirement (Alila et al., 2013). In a reported method, TEMPO in the presence of sodium bromide and sodium hypochlorite is combined with the cellulose fibrils in slurry form to display the hydroxyl groups on the fibrils and replace them with carboxylic groups (Li et al., 2015). Figure 4 gives a schematic diagram illustrating the use of TEMPO for generating CNF. This could also lead to the formation of side reactions. Therefore, to avoid the possibility of side reactions, pretreatment by TEMPO must be carried out at temperatures of $50-60^{\circ} \mathrm{C}$ and under slightly acidic conditions ( $\mathrm{pH} \mathrm{6.0-6.5).}$ As reported, under these conditions, the depolymerization of the cellulose chains does not occur and aldehyde groups are not

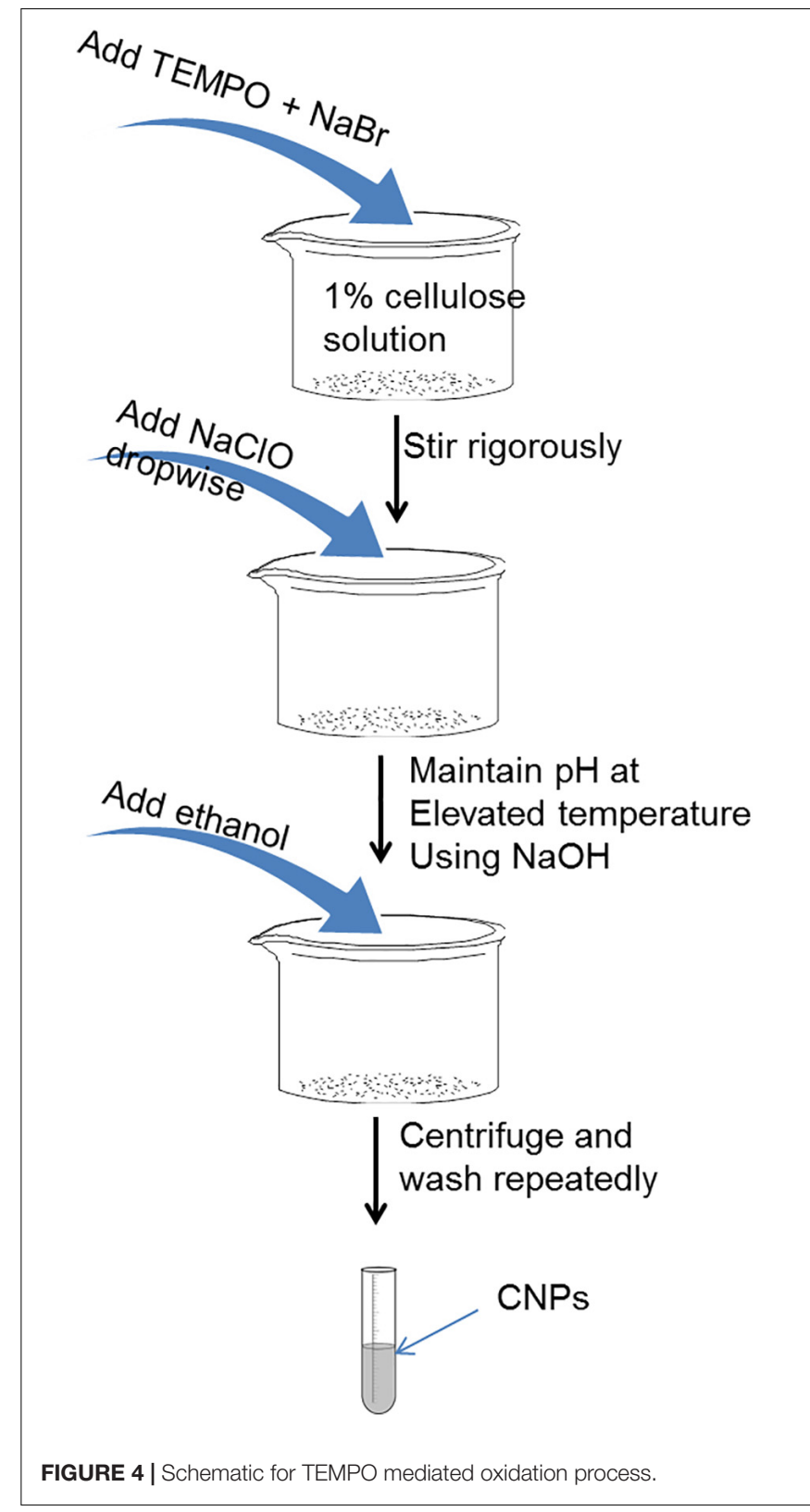

formed (Isogai et al., 2011). Additionally, it was reported that the reaction occurs in the amorphous domains and on the surface of the cellulose fibers. The cellulose begins to disperse in the aqueous solution as the carboxyl content is increased to a certain amount, but the crystalline domains remains undamaged and consequently can be released (Dufresne, 2012).

According to Alila and coworkers, TEMPO-mediated oxidation was achieved by dispersing $5 \mathrm{~g}$ of cellulose fibers in $0.05 \mathrm{M}$ sodium phosphate buffer containing $25 \mathrm{mg}$ of TEMPO, $250 \mathrm{mg}$ of $\mathrm{NaBr}, 10 \mathrm{mmol}$ of sodium chlorite and $2 \mathrm{M}$ sodium hypochlorite and the mixture left for $6 \mathrm{~h}$ at temperature of $60^{\circ} \mathrm{C}$ under stirring (Alila et al., 2013). However, it is important to mention that many researchers still employ ultrasonication after the TEMPO-mediated oxidation but with a reduction in time. 


\section{Challenges of Extraction Processes for Non-woody Lignocellulosic Biomasses}

Cellulose nanoparticles are new generation of nanomaterials that has generated a lot of interest worldwide. It is one of the most important nanomaterials from lignocellulosic biomass with superior physical and chemical properties. It is nontoxic, renewable, and biodegradable. However, the processes of production of CNPs from plants vary. Considering that all plants are composed of cellulose at varying percentages, a good understanding of the factors influencing their extraction could lead to increased production of cellulose from different sources of non-woody plants with similar properties, thereby, relieving some pressure from wood-based sources. Knowing that the properties of the CNPs depend greatly on the extraction and isolation processes, it is considered worthwhile to highlight and expatiate on some of factors that affect or influence their production process. These factors include:

- The amount of hemicellulose and lignin present in the fiber.

- The percentage (\%) of cellulose after purification of the fiber.

- Plant part to be used in the isolation of CNP.

- Proposed application of the extracted CNP and expected properties of the CNP.

Hemicellulose and lignin contents present.

The amount of hemicellulose and lignin present in the biomass is of great importance. Hence, the need to carry out compositional analysis of the biomass prior to deciding on the procedures to adopt becomes necessary. An effective removal of the lignin and hemicellulose will lead to isolation of nanoparticle of averagely similar sizes which eventually gives uniform properties (Kalia et al., 2011; Ng et al., 2015). The presence of lignin and hemicellulose can reduce the thermal stability, mechanical performance, and crystallinity ratio of the CNPs (Jonoobi et al., 2009; Acharya et al., 2011; Faruk et al., 2012). The purpose of the pretreatment stages; prealkalization, alkalization and bleaching is to obtain a celluloserich fiber material (Phanthong et al., 2018). These pre-treatment processes can be repeated many times to ensure maximum removal of the lignin and hemicellulose (Agwuncha et al., 2020). Additionally, the effective removal of these impurities will help clean the fiber surface and modify it so that its hydrophilic tendency is reduced whilst the surface roughness increases drastically. It is important to mention that the sequence of the processes carried out may not be too important, except for the pre-alkalization step. It is inconsequential which comes first between the alkalization and bleaching steps. While many researchers have reported processes that start with alkalization, some handful have also reported steps that star with the bleaching process. The result remains similar either way. The alkalization (mercerization) process is typically carried out using $\mathrm{NaOH}$ or KOH. Although Das et al. (2016) used LiOH for alkalization, the concentration, temperature and time employed varied very widely.

Generally, researchers have reported ranges of concentrations (4-20\%); temperature $\left(45-120^{\circ} \mathrm{C}\right)$ and time (45-120 $\mathrm{min}$ ). Equally, some authors have reported concentrations of $4-7 \%$ as the most appropriate for the removal of hemicellulose in lignocellulosic biomass at $70-80^{\circ} \mathrm{C}$ temperature for $30-60 \mathrm{~min}$. The use of low concentrations at elevated temperatures for the removal of hemicellulose will lead to gradual decomposition of the bond binding it to lignin, thus making it soluble in the alkaline solution with minimal damage to the crystalline region. This can also lead to the removal of more extractibles as mentioned earlier. Low concentration helps to conserve the crystalline region, while higher concentrations of alkaline solution results in the formation of fibrils (Phanthong et al., 2018). An alkaline solution with $15-20 \%$ concentration is considered high and has been used for pretreating the fibers for the preparation of CNF using oxidation and/or mechanical methods (Alila et al., 2013). Most high concentration cooking of fiber for CNF preparation are carried out at high temperature of $120-160^{\circ} \mathrm{C}$ for $1-2 \mathrm{~h}$ (Meng et al., 2019). Thus, as indicated, the desired product will help decide the conditions for any CNP processing.

Bleaching helps in the removal of the lignin from the fibers. As mentioned earlier, the concentration, temperature, time, and liquor ratio (fiber to reagent ratio, $w / v$ ) are very important in the bleaching process, just as it is in the alkalization process. Researchers that have reported the use of sodium chlorite in sodium acetate buffer used concentrations ranging from 1.0$6.0 \%$ sodium chlorite $\left(\mathrm{NaClO}_{2}\right)$ in sodium acetate buffer (Abdul Rahman et al., 2017; Bano and Negi, 2017; Lee et al., 2018; Luzi et al., 2019; Meng et al., 2019). Similarly, some have used 5.0$50.0 \%$ of hydrogen peroxide $\left(\mathrm{H}_{2} \mathrm{O}_{2}\right)$ in $\mathrm{NaOH}$ solution (Oliveira et al., 2016; Wijaya et al., 2017; Coelho et al., 2018; Ovalle-Serrano et al., 2018) or in acetic acid (Marett et al., 2017). This clearly shows that bleaching is usually carried out in mild acidic or alkaline medium. Recently, a total chlorine free (TCF) bleaching procedure was reported by Robles et al. (2018). The bleaching procedure was carried out in three stages. First stage was the alkali oxygen stage (which was repeated twice), in which water (pH 11.0) was stabilized using $\mathrm{NaOH}$ and $\mathrm{MgSO}_{4}$ (0.2 wt\%) for $60 \mathrm{~min}$ at $98^{\circ} \mathrm{C}$ and performed under a pressure of six bar oxygen atmosphere. The second stage, the peroxide stage involved a secondary chelating reaction using $3 \mathrm{M} \mathrm{H}_{2} \mathrm{O}_{2}$ at $\mathrm{pH} 11.0$ with 1:5 $(w / v)$ pentetic acid as chelant, was performed at $105^{\circ} \mathrm{C}$ for $120 \mathrm{~min}$. Finally, the third stage known as alkaline peroxide stage involved the use of a $3 \mathrm{M} \mathrm{H}_{2} \mathrm{O}_{2}$ solution at $\mathrm{pH} 11.0$ and $\mathrm{MgSO}_{4}(0.2 \mathrm{wt} \%)$ for $150 \mathrm{~min}$ at $98^{\circ} \mathrm{C}$ under a pressure of six bar $\mathrm{O}_{2}$ atmosphere.

Most investigations reported revealed that the alkalization and bleaching processes were repeated multiple times to achieve better results. When high concentrations are used, the duration of treatment are reduced to the lowest possible. Many encouraging results have been reported for procedures carried out at room temperature and allowed to stand overnight (i.e., 12$16 \mathrm{~h})$. However, the decision on experimental design remains squarely on the percentages of lignin and hemicellulose of the plant being used.

\section{Percentage of Cellulose After Purification}

Comparable to the alkalization and bleaching processes, the isolation process is dependent on the percentage of cellulose in the treated fiber and the nanoparticles type expected (that 
is cellulose nanofibers, CNF or cellulose nanocrystals, CNC). $\mathrm{CNF}$ are usually produced using mechanical processes, however, to improve the efficiency of the process, chemically mediated oxidation treatments are given to the fiber prior to the mechanical treatment (Liu et al., 2016; Lee et al., 2018). These chemical treatments have led to improvements in the characteristic properties of the CNF. Thus, the CNF size (length and width) are wholly determined by the chemical treatment of the oxidation procedure. The challenge here is in determining the most appropriate chemical reagent for CNF production. However, treatment with already established chemicals and optimizing treatment parameters provides good insights to the best conditions for any extraction to be carried out.

Cellulose nanoparticles are mostly produced by acid mediated cleavage of the cellulose chains at the amorphous region. As mentioned earlier, strong acids such as $\mathrm{H}_{2} \mathrm{SO}_{4}, \mathrm{HCl}$, formic acid, and phosphoric acid are typically used for this process (Ng et al., 2015). The concentration used varies from plant to plant. The duration of the experiment varies from 30-60 min, at temperature ranging from $45-60^{\circ} \mathrm{C}$. It must be emphasized that the higher the concentration of the acid, the lower the time and temperature conditions. Researchers carried out an experiment to investigate the effect of treatment time on acid hydrolysis (Nascimento et al., 2016). Their findings revealed that after $1 \mathrm{~h}$, the process become a mere waste of energy and an additional cost to the process, which is unnecessary. They reached this conclusion when the FTIR, XRD, and TGA analysis showed insignificant differences for samples treated for $1 \mathrm{~h}$ and those treated for $2 \mathrm{~h}$. Also, research findings from Rezende et al. (2011) showed that $4 \% \mathrm{NaOH}$ solution gave the highest cellulose content after pretreatment for $40 \mathrm{~min}$ at $120^{\circ} \mathrm{C}$.

The length of time, concentration of acid solution and temperature employed for the treatment are strongly based on the percentage of cellulose in the treated fibers. A treated fiber with high percentage cellulose is an indication that the amount of impurities (lignin and hemicellulose) is very low. Hence the treated fibers will be high fibrillated. Therefore, reagent will require less energy to penetrate such material and generate the nanoparticles, which can be measured in terms of their crystallinity or nanosize as indicated in Table 3.

\section{Part of Plants Used for the Extraction of CNPs}

Researchers have reported the use of different types and different parts of plant for the extraction of nanocellulose. Alila and coworkers (Alila et al., 2013) used non-woody plants such as basts of flax, hemp and jute and leaves of sisal and abaca; Harini et al. (2018) and Bano and Negi (2017), Marett and collaborators (Marett et al., 2017) and Naduparambath et al. (2018) used shells of walnut, groundnut, pistachio and sago, respectively. Cherian et al. (2010), Basta et al. (2014), Flauzino Neto et al. (2013), and Manzato et al. (2017) used pineapple leaves, rice straw, soy hull, and tucuma's endocarp, respectively. Agricultural wastes such as jackfruit peel, sugarcane bagasse, palm fruit bunch, coconut coir, tea leaf and North African grass have also been reportedly used for nanocellulose extraction (Zhang et al., 2016;
Abdul Rahman et al., 2017; Feng et al., 2018; Luzi et al., 2019; Trilokesh and Uppuluri, 2019). These different parts of plants will vary widely in their composition and so requires a good understanding and design of extraction procedure for each specific part or plant.

According to Phanthong and coworkers, the different extraction methods for the isolation of CNP will continue to result in differences in properties of CNPs being obtained (Phanthong et al., 2018). This is not limited to the composition of these parts, but also the degree of polymerization (DP) of the cellulose. The stem of plants is believed to have high content of cellulose which must have had hemicellulose and lignin well embedded into the cellulose. Therefore, extraction procedure should consider this vital point and it should be noted that this is closely associated to the age of the plant as well.

Under similar hydrolysis conditions, the dimensions and crystallinity of the nanocrystalline particles is dependent on the origin of the cellulose feedstock (Habibi et al., 2010; Li and Ragauskas, 2011; Ioelovich, 2014). For example, tunicate samples yielded extremely long and crystalline nanoparticles with a high aspect ratio after acid hydrolysis, whilst wood cellulose generated shorter and less crystalline nanoparticles with a lower aspect ratio. Largely, isolation of nanocrystalline particles from cellulose of several terrestrial plants have lengths of $100-300 \mathrm{~nm}$ and lateral sizes reaching $4-20 \mathrm{~nm}$, but those sequestered from non-terrestrial sources, such as algae, tunicate and bacteria cellulose are thicker and longer (Hubbe et al., 2008; Habibi et al., 2010; Li and Ragauskas, 2011; Peng et al., 2011; Ioelovich, 2014).

\section{Expected Properties and Planned Application of the Nanocellulose}

The properties and application of CNPs are two factors that must be considered together. The properties of CNPs determine the application best suited therein. Hence, one can design extraction procedures to give different properties of CNPs from the same plant sources. CNC or CNF are remarkably different from one another. According to Kargarzadeh et al. (2018), CNF are usually 3-50 $\mathrm{nm}$ in diameter, few $\mu \mathrm{m}$ in length and have crystallinity below 50\%. This has encouraged increase in tensile strength and modulus when used as fillers in hydrophilic polymers. Application of CNF include support for antibacterial coating, used as rheology modifier, as support for catalysts and sensors, tissue engineering, scaffold and network structures. Other applications include food coating, dental application and use as biocompatible nanocomposites.

On the other hand, CNC are of 5-20 nm in diameter; 10$500 \mathrm{~nm}$ in length; with crystallinity of $60-90 \%$. CNC can affect the tensile strength and modulus of compounded polymers positively; its thermal stability and tensile strength are much lower than those of CNF. But an important mention is that its tensile modulus is much higher when compared to CNF. CNCs have been successfully employed as a vehicle for drug delivery, diaphragm in earphones and additives to drilling fluids. Other applications include biomimetic foams, optical applications, water pollution remediation, toughening of paper. Similar to 
CNF, CNC can be used as rheology modifier, catalysts and sensors support, for tissue engineering and scaffold.

With the above categorization, except for general research purpose, isolation of nanocellulose should be based on definite application requiring specific properties. Panaitescu et al. (2013) prepared composite of polyamide by reinforcing the polymer with $\mathrm{CNCs}$ and CNFs, respectively. The PA-CNC nanocomposites exhibited 25\% rise in Young's modulus and $10 \%$ increase in yield strength with a $1 \%$ CNC loading. The improvement was observed up to $5 \mathrm{wt} \%$ loading of CNCs. These improvements in properties were attributed to good interaction between the matrix and the nanoparticles which gave rise to high stiffness. However, it was insufficient to inhibit the brittleness of the composites. On the other hand, the PA-CNF nanocomposites were reported to have improved thermal stability, bending and izod impact strength and storage modulus. The authors attributed these improvements to the exceptional dispersal and unique high aspect ratio of the CNFs.

In another study by researchers, the effect of CNFs and CNCs on the properties of films of polyethylene oxide (PEO) also known as polyethylene glycol (PEG) was investigated (Xu et al., 2013). Their findings revealed that PEO-CNF nanocomposites demonstrated remarkable increase in the yield strength and in the plastic flow stress, but the PEO-CNC nanocomposites exhibited no change in the yield strength and in the plastic flow when compared to that of the neat polymer. Furthermore, the PEO-CNF films were translucent while the PEO-CNC films were optically transparent, an indication of better dispersion of the CNC due to its smaller sizes compared to that of CNF which formed agglomeration. In addition, the melt temperature, heat of fusion and crystallinity of both CNC and CNF films were identified to be rather lower than that of the neat polymer. This was reportedly attributed to confinement effect of the nanoparticles. According to the authors, the nanoparticles prevented the diffusion and folding of the chain at the crystal growth front, thereby resulting in thinner PEO lamellae.

The nanocomposites of CNFs proved higher modulus and strength than those prepared using CNCs. This is attributed to the fiber entanglement and large aspect ratio of the CNFs. However, because of the large fiber agglomeration in CNF nanocomposites, the strain-at-failure is always observed to be lower compared to CNCs nanocomposites. Therefore, the intended application must be considered in preparation of either cellulose nanoparticles CNPs. The extraction of CNPs from tea leaf by Abdul Rahman and coworkers (Abdul Rahman et al., 2017) was done by pretreating the dried leaves with $4 \% \mathrm{NaOH}$ solution for $3 \mathrm{~h}$ at $80^{\circ} \mathrm{C}$. This process was repeated four times to achieve an approximately $67.4 \%$ removal of hemicellulose and lignin and after bleaching the percentage removed increase to 89.6 and $90.4 \%$, respectively. In another study by Luzi et al. (2019) to isolate CNP from North African glass, the authors used a combination of two bleaching methods in order to ensure maximum removal of non-cellulosic components.

Examples of extraction procedures for selected non-woody biomasses and their applications.

In a study to investigate the possible application of CNCs extracted from passion fruit peels, Wijaya used $52 \%$ sulfuric acid solution for the extraction at $50^{\circ} \mathrm{C}$ for 60 min with a liquor ratio of 1:10 fibers: reagent ratio, $w / v$ (Wijaya et al., 2017). The extracted CNCs had a particle size ranging from 103.0-173.5 nm with reportedly good thermal properties. The maximum yield of CNCs extracted was $58.1 \pm 1.7 \%$ and the CNCs demonstrated good absorption capacity at $\mathrm{pH} 3.0$ and release capacity of $82 \%$ at $\mathrm{pH}$ 7.2. This showed that the CNCs from waste such as passion fruit peels can be used in drug delivery. Also, the extraction procedure used leaves room for improvement when compared to similar studies by other researchers (El Achaby et al., 2018a). El Achaby and colleagues chemically treated red algae waste using alkali, bleach and acid hydrolysis treatments to obtain pure cellulose microfibers and CNC. In their investigation, they used $64 \mathrm{wt} \%$ sulfuric acid at $50^{\circ} \mathrm{C}$ for $80 \mathrm{~min}$ with liquor ratio of $1: 10$ to carry out the acid hydrolysis. Their results revealed the successful isolation of needle-like shaped CNC with nanometric scale of the particles observed to be between $5.2 \pm 2.9-9.1 \pm 3.1 \mathrm{~nm}$ and $285.4 \pm 36.5-315.7 \pm 30.3 \mathrm{~nm}$ in diameter and length, respectively. The CNC were utilized as nanofillers for polyvinyl alcohol (PVA)-based nanocomposite films production which displayed improvements in optical transparency, tensile and thermal properties. With just $8 \mathrm{wt} \% \mathrm{CNC}$ additions to the PVA matrix, an increase of approximately $215 \%$ in the Young's modulus, $150 \%$ in the tensile strength and $45 \%$ in the toughness was observed. Therefore, the increase of acid concentration from $52 \mathrm{wt}$ to $64 \mathrm{wt} \%$ and treatment time from 60 to $80 \mathrm{~min}$ led to reduction in nanosizes and the yield\% of the CNCs produced.

Rampazzo et al. (2017) investigated the chances of obtaining CNCs from lignocellulose raw materials such as cotton and kraft pulp. They used ammonium persulfate (APS) to isolate CNCs. From their results, the gas barrier properties of the coating obtained by using CNCs from the wastes were remarkable. The permeability values for oxygen and $\mathrm{CO}_{2}$ obtained were hundreds of times lower than those of equal thickness from the usual polymer. The analysis of the properties of the extracted CNCs showed that the particles sizes ranged from 130-170 nm, which were considered too high. Therefore, if the processing conditions are varied a little, there is the possibility of isolating particles with smaller diameters.

Tissue engineering is one area of immense application of cellulose nanocomposites. Costa et al. (2013) prepared bionanocomposite of polyvinyl alcohol (PVA) with nanofibers from pineapple and characterized them for possible applications in the biomedical field. The pineapple leaf fibers were extracted using autoclave and kept under $138 \mathrm{KPa}$ pressure for $1 \mathrm{~h}$. The fibers were bleached using a mixture of $\mathrm{NaOH}$ and acetic acid and a 1:3 $\mathrm{NaClO}_{2}$ solution and repeated six times to achieve a cellulose percentage content of $87 \%$. The steam explosion process was repeated eight times to obtain nanofibrils yield of $69 \%$, after treating the bleached cellulose with $\mathrm{C}_{2} \mathrm{H}_{2} \mathrm{O}_{4}$ (oxalic acid) of $11 \%$ concentration. The obtained CNFs had better thermal properties and higher crystallinity. However, literature has shown that TEMPO mediated oxidation leads to reduction in nanosize better than what was obtained.

Kusmono et al. (2020) carried out extraction of CNPs from ramie fibers using sulfuric acid hydrolysis. The research team varied the hydrolysis temperature and time, to evaluate their 
influences on the properties of the extracted CNCs. From the characterization results, it was reported that the crystallinity, dimensions and thermal stability of the CNC obtained were highly affected. The optimal results were obtained when the hydrolysis parameters were set at $45^{\circ} \mathrm{C}$ for $30 \mathrm{~min}$ using $58 \%$ acid solution at 1:20 $(w / v)$ liquor ratio. Using these parameters, a rodlike morphology with good thermal property, $90.8 \%$ crystallinity, $6.7 \mathrm{~nm}$ diameters and $145.6 \mathrm{~nm}$ lengths was obtained.

Sherif and colleagues exploited the biowastes of palm tree for the possible production of lignin-rich CNPs which can be applied in water treatment processes and drug delivery (Mehanny et al., 2020). In their work, three different biowastes from palm tree, namely coir, leaves and fronds, were subjected to alkalization and acid hydrolysis, omitting the bleaching step. Alkalization was done using $10 \% \mathrm{NaOH}$ at $160^{\circ} \mathrm{C}$ for $2 \mathrm{~h}$ and using 1:10 $(w / v)$ liquor ratio, while acid hydrolysis was done using $20 \%$ sulfuric acid at $120^{\circ} \mathrm{C}$ for $30 \mathrm{~min}$ with 1:20 $(w / v)$ liquor ratio. The obtained CNPs gave properties that varied widely. Also, the crystallinity of the particles obtained decreased substantially after the acid hydrolysis process, indicating a drastic destruction of the crystalline region at the selected treatment condition. The low acid concentration was compensated with the high treatment temperature. Although, the researchers reported to have succeeded in preparing lignin-rich CNPs as planned, the variation in the properties of the CNPs obtained required a further review of the treatment conditions. Lignin-rich CNPs have been reported to be good adsorbent for heavy metals removal and drug delivery (Rangan et al., 2017; Figueiredo et al., 2018; Huang et al., 2019).

Pili pulp waste, which is a waste obtained from pili essential oil production, was used for the preparation of CNPs by researchers (Bongao et al., 2020). According to the report, the biowaste was boiled in water for $20 \mathrm{~min}$ at $100^{\circ} \mathrm{C}$ and then treated with $1.0 \mathrm{M} \mathrm{NaOH}$ alkaline solution for $2 \mathrm{~h}$ at $80^{\circ} \mathrm{C}$ before bleaching with $\mathrm{NaClO}_{2}$ at $100^{\circ} \mathrm{C}$ for $1 \mathrm{~h}$ using $1: 20(w / v)$ liquor ratio. Acid hydrolysis was done using 64\% sulfuric acid at liquor ratio of $1: 20(w / v)$ and treating for 30-60 min at $50^{\circ} \mathrm{C}$. The characterization results obtained, showed that the procedure as applied generated microcellulose particles on the average. The low concentration of the alkaline solution used shows that the cellulosic material may not have been adequately removed. The presence of hemicellulose and lignin observed in the FTIR spectra as presented by the authors confirmed this. It is important to emphasize that the production of CNPs of averagely similar sizes and properties, requires adequate removal

\section{REFERENCES}

Abd El-Aziz, M. E., Kamal, K. H., Ali, K. A., Abdel-Aziz, M. S., and Kamel, S. (2018). Biodegradable grafting cellulose/clay composites for metal ions removal. Int. J. Biol. Macromol. 118, 2256-2264. doi: 10.1016/j.ijbiomac.2018. 07.105

Abdul Khalil, H. P. S., Davoudpour, Y., Islam, M. N., Mustapha, A., Sudesh, K., Dungani, R., et al. (2014). Production and modification of nanofibrillated cellulose using various mechanical processes: a review. Carbohydr. Polym. 99, 649-665. doi: 10.1016/j.carbpol.2013.08.069

Abdul Khalil, H. P. S., Davoudpour, Y., Saurabh, C. K., Hossain, S., Adnan, A. S., Dungani, R., et al. (2016). A review on nanocellulosic fibres as new material for of the non-cellulosic impurities, hence the need to carry out the pre-treatment procedures multiple times.

\section{CONCLUSION}

Cellulose nanoparticles are materials with amazing properties and are finding application in every field of human endeavor. The advantages of scaling down to nanocellulose from lignocellulose biomass are numerous. Rather than utilizing woody biomasses which are getting depleted, non-woody lignocellulosic biomasses are abundant in our immediate environment and underutilized. They are discarded as worthless materials through burning or used as composting. However, the conversion of these groups of waste to CNPs will go a long way in impacting our environment. In this write-up, we have been able to successfully highlight the relevance of specific extraction processes and procedures which influence the extraction of CNPs. We aim to draw specific attention to non-woody biomasses and the importance of understanding of the challenges of their extraction processes, so as to promote their utilization to the general benefit of mankind and the environment.

\section{AUTHOR CONTRIBUTIONS}

SO and SA: conceptualization, methodology, data curation, experimental, and writing-original draft preparation. NM and GS: resources and writing-reviewing and editing. EM: resources, writing-reviewing and editing, supervision, and administration. NR: supervision, project administration, funding acquisition, resources, and writing-reviewing and editing. All authors contributed to the article and approved the submitted version.

\section{ACKNOWLEDGMENTS}

The financial assistance of the University of Zululand and the National Research Foundation, South Africa through the South African Research Chair Initiative (SARChI) is hereby acknowledged. SO would like to thank the National Research Foundation (NRF) for funding under South African Research Chair for Nanotechnology. The authors recognize the contributions of the University of Johannesburg through the GES award, for access to resources, and database.

sustainable packaging: process and applications. Renew. Sustai. Energy Rev. 64, 823-836. doi: 10.1016/j.rser.2016.06.072

Abdul Rahman, N. H., Chieng, B. W., Ibrahim, N. A., and Abdul Rahman, N. (2017). Extraction and characterization of cellulose nanocrystals from tea leaf waste fibers. Polymers 9:588. doi: 10.3390/polym9110588

Abraham, E., Deepa, B., Pothen, L. A., Cintil, J., Thomas, S., John, M. J., et al. (2013). Environmental friendly method for the extraction of coir fibre and isolation of nanofibre. Carbohydr. Polym. 92, 1477-1483. doi: 10.1016/j.carbpol. 2012.10.056

Acharya, S. K., Mishra, P., and Mehar, S. K. (2011). Effect of surface treatment on the mechanical properties of bagasse fiber reinforced polymer composite. BioResources 6, 3155-3165. 
Adel, A. M., El-Wahab, Z. H. A., Ibrahim, A. A., and Al-Shemy, M. T. (2010). Characterization of microcrystalline cellulose prepared from lignocellulosic materials. part I. acid catalyzed hydrolysis. Bioresour. Technol. 101, 4446-4455. doi: 10.1016/j.biortech.2010.01.047

Agwuncha, S. C., Anusionwu, C. G., Owonubi, S. J., Sadiku, E. R., Busuguma, U. A., and Ibrahim, I. D. (2019). "Extraction of cellulose nanofibers and their eco/friendly polymer composites," in Sustainable Polymer Composites and Nanocomposites, eds Inamuddin, T. Sabu, A. M. Asiri, et al. (New York, NY: Springer International Publishing). doi: 10.1007/978-3-030-05399-4_2

Agwuncha, S. C., Owonubi, S., Fapojuwo, D. P., Abdulkarim, A., Okonkwo, T. P., and Makhatha, E. M. (2020). Evaluation of mercerization treatment conditions on extracted cellulose from shea nut shell using FTIR and thermogravimetric analysis. Mater. Today. Proc. 38, 958-963. doi: 10.1016/j.matpr.2020.05.473

Alila, S., Besbes, I., Vilar, M. R., Mutjé, P., and Boufi, S. (2013). Non-woody plants as raw materials for production of microfibrillated cellulose. (MFC): a comparative study. Ind. Crops Prod. 41, 250-259.

Bacakova, L., Pajorova, J., Bacakova, M., Skogberg, A., Kallio, P., Kolarova, K., et al. (2019). Versatile application of nanocellulose: from industry to skin tissue engineering and wound healing. Nanomaterials 9:164. doi: 10.3390/ nano9020164

Balakrishnan, P., Geethamma, V. G., Sreerag, G., Martin, G. T., Volova, T., Sabu, T., et al. (2019). Thermal, biodegradation and theoretical perspectives on nanoscale confinement in starch/cellulose nanocomposite modified via green crosslinker. Int. J. Biol. Macromol. 134, 781-790. doi: 10.1016/j.ijbiomac.2019.05.088

Bano, S., and Negi, Y. S. (2017). Studies on cellulose nanocrystals isolated from groundnut shells. Carbohydr. Polym. 157, 1041-1049. doi: 10.1016/j.carbpol. 2016.10.069

Basta, A. H., El-Saied, H., and Lofty, V. F. (2014). Performance assessment of deashed and dewaxed rice straw on improving the quality of RS-based composites. RSC Adv. 4, 21794-21801. doi: 10.1039/c4ra00858h

Bledzki, A. (1999). Composites reinforced with cellulose based fibres. Prog. Polym. Sci. 24, 221-274. doi: 10.1016/s0079-6700(98)00018-5

Bongao, H. C., Gabatino, R. R. A., Arias, C. F. H., and Magdaluyo, E. R. Jr. (2020). Micro/nanocellulose from waste pili. (Canarium ovatum). pulp as a potential anti-ageing ingredient for cosmetic formulations. Mater. Today. Proc. $22,275-280$.

Bruice, P. Y. (2003). Organic Chemistry, 4th Edn. London: Pearson.

Buranov, A. U., and Mazza, G. (2008). Lignin in straw of herbaceous crops. Ind. Crops Prod. 28, 237-259. doi: 10.1016/j.indcrop.2008.03.008

Burhenne, L., Messmer, J., Aicher, T., and Laborie, M. P. (2013). The effect of the biomass components lignin, cellulose and hemicellulose on TGA and fixed bed pyrolysis. J. Anal. Appl. Pyrolysis 101, 177-184. doi: 10.1016/j.jaap.2013.01.012

Chen, W., Yu, H., Liu, Y., Hai, Y., Zhang, M., and Chen, P. (2011). Isolation and characterization of cellulose nanofibers from four plant cellulose fibers using a chemical-ultrasonic process. Cellulose 18, 433-442. doi: 10.1007/s10570-0119497-z

Cherian, B. M., Leão, A. L., de Souza, S. F., Thomas, S., Pothan, L. A., and Kottaisamy, M. (2010). Isolation of nanocellulose from pineapple leaf fibres by steam explosion. Carbohydr. Polym. 81, 720-725. doi: 10.1016/j.carbpol.2010. 03.046

Coelho, C. C. S., Michelin, M., Miguel, A. C., Catarina, G., Renata, V. T., Otniel, F. S., et al. (2018). Cellulose nanocrystals from grape pomace: production, properties and cytotoxicity assessment. Carbohydr. Polym. 192, 327-336. doi: 10.1016/j.carbpol.2018.03.023

Costa, L. M. M., de Olyveira, G. M., Cherian, B. M., Leão, A. L., de Souza, S. F., and Ferreira, M. (2013). Bionanocomposites from electrospun PVA/pineapple nanofibers/Stryphnodendron adstringens bark extract for medical applications. Ind. Crops Prod. 41, 198-202. doi: 10.1016/j.indcrop.2012.04.025

Dacrory, S., Abou-Yousef, H., Kamel, S., and Turky, G. (2019). Development of biodegradable semiconducting foam based on micro-fibrillated cellulose/CuNPs. Int. J. Biol. Macromol. 132, 351-359. doi: 10.1016/j.ijbiomac.2019. 03.156

Das, A. M., Hazarika, M. P., Goswami, M., Yadav, A., and Khound, P. (2016). Extraction of cellulose from agricultural waste using Montmorillonite K10/LiOH and its conversion to renewable energy: biofuel by using Myrothecium gramineum. Carbohydr. Polym. 141, 20-27.

Deepa, B., Eldho, A., Bibin, M. C., Alexander, B., Jonny, J. B., Laly, A. P., et al. (2011). Structure, morphology and thermal characteristics of banana nano fibers obtained by steam explosion. Bioresour. Technol. 102, 1988-1997. doi: 10.1016/j.biortech.2010.09.030
Demirbaş, A. (2005). Estimating of structural composition of wood and non-wood biomass samples. Energy Sour. 27, 761-767. doi: 10.1080/00908310490450971

Dufresne, A. (2012). Nanocellulose, from Nature to High Performance Tailored Materials. Berlin: De Gruyter.

Dufresne, A. (2013). Nanocellulose: a new ageless bionanomaterial. Mater Today 16, 220-227. doi: 10.1016/j.mattod.2013.06.004

El Achaby, M., Kassab, Z., Aboulkas, A., Gaillard, C., and Barakat, A. (2018a). Reuse of red algae waste for the production of cellulose nanocrystals and its application in polymer nanocomposites. Int. J. Biol. Macromol. 106, 681-691. doi: 10.1016/j.ijbiomac.2017.08.067

El Achaby, M., Kassab, Z., Barakat, A., and Aboulkas, A. (2018b). Alfa fibers as viable sustainable source for cellulose nanocrystals extraction: application for improving the tensile properties of biopolymer nanocomposite films. Ind. Crops Prod. 112, 499-510. doi: 10.1016/j.indcrop.2017.12.049

Faruk, O., Bledzki, A. K., Fink, H.-P., and Sain, M. (2012). Biocomposites reinforced with natural fibers: 2000-2010. Prog. Polym. Sci. 37, 1552-1596. doi: 10.1016/j.progpolymsci.2012.04.003

Feng, Y. H., Cheng, T. Y., Yang, W. G., Ma, P. T., He, H. Z., Yin, X. C., et al. (2018). Characteristics and environmentally friendly extraction of cellulose nanofibrils from sugarcane bagasse. Ind. Crops Prod. 111, 285-291. doi: 10.1016/j.indcrop. 2017.10.041

Figueiredo, P., Lintinen, K., Hirvonen, J. T., Kostiainen, M. A., and Santos, H. A. (2018). Properties and chemical modifications of lignin: towards lignin-based nanomaterials for biomedical applications. Prog. Mater. Sci. 93, 233-269.

Flauzino Neto, W. P., Silvério, H. A., Dantas, N. O., and Pasquini, D. (2013). Extraction and characterization of cellulose nanocrystals from agro-industrial residue - soy hulls. Ind. Crops Prod. 42, 480-488. doi: 10.1016/j.indcrop.2012. 06.041

Fortunati, E., Rinaldi, S., Peltzer, M., Bloise, N., Visai, L., Kenny, J. M., et al. (2014). Nano-biocomposite films with modified cellulose nanocrystals and synthesized silver nanoparticles. Carbohydr. Polym. 101, 1122-1133. doi: 10.1016/j.carbpol. 2013.10.055

Frone, A. N., Chiulan, I., Panaitescu, D. M., Nicolae, C. A., Ghiurea, M., and Galan, A.-M. (2017). Isolation of cellulose nanocrystals from plum seed shells, structural and morphological characterization. Mater. Lett. 194, 160-163.

George, M., Mussone, P. G., and Bressler, D. C. (2015). Modification of the cellulosic component of hemp fibers using sulfonic acid derivatives: surface and thermal characterization. Carbohydr. Polym. 134, 230-239. doi: 10.1016/ j.carbpol.2015.07.096

Haafiz, M. K. M., Eichhorn, S. J., Hassan, A., and Jawaid, M. (2013). Isolation and characterization of microcrystalline cellulose from oil palm biomass residue. Carbohydr. Polym. 93, 628-634. doi: 10.1016/j.carbpol.2013.01.035

Haafiz, M. K. M., Hassan, A., Zakaria, Z., and Inuwa, I. M. (2014). Isolation and characterization of cellulose nanowhiskers from oil palm biomass microcrystalline cellulose. Carbohydr. Polym. 103, 119-125. doi: 10.1016/j. carbpol.2013.11.055

Habibi, Y. (2014). Key advances in the chemical modification of nanocelluloses. Chem. Soc. Rev. 43, 1519-1542. doi: 10.1039/c3cs60204d

Habibi, Y., Lucia, L. A., and Rojas, O. J. (2010). Cellulose nanocrystals: chemistry. self-assembly, and applications. Chem. Rev. 110, 3479-3500. doi: 10.1021/ cr900339w

Hamad, K., Kaseem, M., Ayyoob, M., Joo, J., and Deri, F. (2018). Polylactic acid blends: the future of green, light and tough. Prog. Polym. Sci. 85, 83-127. doi: 10.1016/j.progpolymsci.2018.07.001

Harini, K., Chandra Mohan, C., Ramya, K., Karthikeyan, S., and Sukumar, M. (2018). Effect of Punica granatum peel extracts on antimicrobial properties in walnut shell cellulose reinforced bio-thermoplastic starch films from cashew nut shells. Carbohydr. Polym. 184, 231-242. doi: 10.1016/j.carbpol.2017.12.072

Heredia, A., Jiminez, A., and Guillin, R. (1995). Composition of plant cell walls. Zeitschrift fr Lebensmittel-Untersuchung und -Forschung 200, 24-31. doi: 10. 1007/bf01192903

Hivechi, A., Bahrami, S. H., and Siegel, R. A. (2019). Drug release and biodegradability of electrospun cellulose nanocrystal reinforced polycaprolactone. Mater. Sci. Eng. C. Mater. Biol. Appl. 94, 929-937. doi: 10.1016/j.msec.2018.10.037

Huang, Y., Nair, S. S., Chen, H., Fei, B., Yan, N., and Feng, Q. (2019). Lignin-rich nanocellulose fibrils isolated from parenchyma cells and fiber cells of western red cedar bark. ACS Sustain. Chem. Eng. 7, 15607-15616.

Hubbe, M. A., Rojas, O. J., Lucia, L. A., and Sain, M. (2008). Cellulosic nanocomposites: a review. BioResources 3, 929-980. 
Ilyas, R., Sapuan, S., Ishak, M., and Zainudin, E. (2017). Effect of delignification on the physical, thermal, chemical, and structural properties of sugar palm fibre. BioResources 12, 8734-8754.

Ilyas, R. A., Sapuan, S. M., and Ishak, M. R. (2018). Isolation and characterization of nanocrystalline cellulose from sugar palm fibres. (Arenga pinnata). Carbohydr. Polym. 181, 1038-1051. doi: 10.1016/j.carbpol.2017.11.045

Indumathi, M. P., Saral Sarojini, K., and Rajarajeswari, G. R. (2019). Antimicrobial and biodegradable chitosan/cellulose acetate phthalate/ $\mathrm{ZnO}$ nano composite films with optimal oxygen permeability and hydrophobicity for extending the shelf life of black grape fruits. Int. J. Biol. Macromol. 132, 1112-1120. doi: 10.1016/j.ijbiomac.2019.03.171

Ioelovich, M. (2014). Peculiarities of cellulose nanoparticles. TAPPI J. 13, 45-51. doi: 10.32964/tj13.5.45

Isogai, A., Saito, T., and Fukuzumi, H. (2011). TEMPO-oxidized cellulose nanofibers. Nanoscale 3, 71-85. doi: 10.1039/c0nr00583e

Johar, N., Ahmad, I., and Dufresne, A. (2012). Extraction, preparation and characterization of cellulose fibres and nanocrystals from rice husk. Ind. Crops Prod. 37, 93-99. doi: 10.1016/j.indcrop.2011.12.016

Jonoobi, M., Harun, J., Mishra, M., and Oksman, K. (2009). Chemical composition, crystallinity and thermal degradation of bleached and unbleached kenaf bast. (Hibiscus cannabinus). pulp and nanofiber. BioResources 4, 626-639.

Kalia, S., Dufresne, A., Cherian, B. M., Kaith, B. S., Avérous, L., Njuguna, J., et al. (2011). Cellulose-based bio- and nanocomposites: a review. Int. J. Polym. Sci. 2011, 1-35. doi: 10.1155/2011/837875

Kargarzadeh, H., Ahmad, I., Abdullah, I., Dufresne, A., Zainudin, S. Y., and Sheltami, R. M. (2012). Effects of hydrolysis conditions on the morphology, crystallinity, and thermal stability of cellulose nanocrystals extracted from kenaf bast fibers. Cellulose 19, 855-866. doi: 10.1007/s10570-012-9684-6

Kargarzadeh, H., Ioelovich, M., Ahmad, I., Thomas, S., Dufresne, A. (2017). "Methods for extraction of nanocellulose from various sources, " in Handbook of Nanocellulose and Cellulose Nanocomposites, 1st Edn, eds H. Kargarzadeh, I. Ahmad, S. Thomas, and A. Dufresne. Weinheim: Wiley-VCH Verlag GmbH \& Co. $\mathrm{KGaA}$

Kargarzadeh, H., Marcos, M., Deepu, G., Ishak, A., Sabu, T., Alain, D., et al. (2018). Advances in cellulose nanomaterials. Cellulose 25, 2151-2189. doi: 10.1007/ s10570-018-1723-5

Kassab, Z., Syafri, E., Tamraoui, Y., Hannache, H., and El Achaby, M. (2020). Characteristics of sulfated and carboxylated cellulose nanocrystals extracted from Juncus plant stems. Int. J. Biol. Macromol. 154, 1419-1425.

Klemm, D., Kramer, F., Moritz, S., Lindström, T., Ankerfors, M., Gray, D., et al. (2011). Nanocelluloses: a new family of nature-based materials. Angew Chem. Int. Ed. 50, 5438-5466. doi: 10.1002/anie.201001273

Kusmono, Listyanda, R. F., Wildan, M. W., and Ilman, M. N. (2020). Preparation and characterization of cellulose nanocrystal extracted from ramie fibers by sulfuric acid hydrolysis. Heliyon 6:e05486. doi: 10.1016/j.heliyon.2020.e05486

Kvavadze, E., Bar-Yosef, O., Belfer-Cohen, A., Boaretto, E., Jakeli, N., Matskevich, Z., et al. (2009). 30,000-year-old wild flax fibers. Science 325, 1359-1359.

Lee, H.-R., Kim, K., Mun, S. C., Chang, Y. K., and Choi, S. Q. (2018). A new method to produce cellulose nanofibrils from microalgae and the measurement of their mechanical strength. Carbohydr. Polym. 180, 276-285. doi: 10.1016/j.carbpol. 2017.09.104

Lee, H. V., Hamid, S. B. A., and Zain, S. K. (2014). Conversion of lignocellulosic biomass to nanocellulose: structure and chemical process. ScientificWorldJournal 2014, 631013-631013. doi: 10.1155/2014/631013

Lee, M., Heo, M. H., Lee, H.-H., Kim, Y.-W., and Shin, J. (2017). Tunable softening and toughening of individualized cellulose nanofibers-polyurethane urea elastomer composites. Carbohydr. Polym. 159, 125-135. doi: 10.1016/j. carbpol.2016.12.019

Lei, W., Fang, C. Q., Zhou, X., Yin, Q., Pan, S., Yang, R., et al. (2018). Cellulose nanocrystals obtained from office waste paper and their potential application in PET packing materials. Carbohydr. Polym. 181, 376-385. doi: 10.1016/j.carbpol. 2017.10.059

Li, J., Wei, X., Wang, Q., Chen, J., Chang, G., Kong, L., et al. (2012). Homogeneous isolation of nanocellulose from sugarcane bagasse by high pressure homogenization. Carbohydr. Polym. 90, 1609-1613. doi: 10.1016/j. carbpol.2012.07.038

Li, R., Fei, J., Cai, Y., Li, Y., Feng, J., and Yao, J. (2009). Cellulose whiskers extracted from mulberry: a novel biomass production. Carbohydr. Polym. 76, 94-99. doi: 10.1016/j.carbpol.2008.09.034
Li, Y., and Ragauskas, A. (2011). "Cellulose nano whiskers as a reinforcing filler in polyurethanes," in Advances in Diverse Industrial Applications of Nanocomposites, ed. B. Reddy (London: IntechOpen).

Li, Y., Yue, Z., Qi, C., Liu, Y. S., Hong, Z., Yang, Y., et al. (2015). Multifunctional fullerene derivative for interface engineering in perovskite solar cells. J. Am. Chem. Soc. 137, 15540-15547. doi: 10.1021/jacs.5b10614

Liu, C., Li, B., Du, H., Dong, L. V., Zhang, Y., Yu, G., et al. (2016). Properties of nanocellulose isolated from corncob residue using sulfuric acid, formic acid, oxidative and mechanical methods. Carbohydr. Polym. 151, 716-724. doi: 10. 1016/j.carbpol.2016.06.025

Liu, Z., Li, X., Xie, W., and Deng, H. (2017). Extraction, isolation and characterization of nanocrystalline cellulose from industrial kelp. (Laminaria japonica). waste. Carbohydr. Polym. 173, 353-359. doi: 10.1016/j.carbpol.2017. 05.079

Lorenz, M., Sattler, S., Reza, M., Bismarck, A., and Kontturi, E. (2017). Cellulose nanocrystals by acid vapour: towards more effortless isolation of cellulose nanocrystals. Faraday Discuss. 202, 315-330. doi: 10.1039/c7fd00053g

Lu, P., and Hsieh, Y.-L. (2010). Preparation and properties of cellulose nanocrystals: rods, spheres, and network. Carbohydr. Polym. 82, 329-336. doi: 10.1016/j.carbpol.2010.04.073

Luzi, F., Fortunati, E., Puglia, D., Lavorgna, M., Santulli, C., Kenny, J. M., et al. (2014). Optimized extraction of cellulose nanocrystals from pristine and carded hemp fibres. Ind. Crops Prod. 56, 175-186. doi: 10.1016/j.indcrop.2014. 03.006

Luzi, F., Puglia, D., Sarasini, F., Tirillò, J., Maffei, G., Zuorro, A., et al. (2019). Valorization and extraction of cellulose nanocrystals from North African grass: Ampelodesmos mauritanicus. (Diss). Carbohydr. Polym. 209, 328-337. doi: 10. 1016/j.carbpol.2019.01.048

Manzato, L., Rabelo, L. C. A., de Souza, S. M., da Silva, C. G., Rabelo, D., John, S., et al. (2017). New approach for extraction of cellulose from tucumãs endocarp and its structural characterization. J. Mol. Struct. 1143, 229-234.

Marett, J., Aning, A., and Foster, E. J. (2017). The isolation of cellulose nanocrystals from pistachio shells via acid hydrolysis. Ind. Crops Prod. 109, 869-874. doi: 10.1016/j.indcrop.2017.09.039

Marques, G., Rencoret, J., Gutiérrez, A., Alfonso, J., and del Río, J. C. (2010). Evaluation of the chemical composition of different non-woody plant fibers used for pulp and paper manufacturing. Open Agric. J. 4, 93-101.

McKendry, P. (2002). Energy production from biomass. (part 1): overview of biomass. Bioresour. Technol. 83, 37-46. doi: 10.1016/s0960-8524(01)00118-3

Mehanny, S., Abu-El Magd, E. E., Ibrahim, M., Farag, M., Gil-San-Millan, R., Navarro, J., et al. (2020). Extraction and characterization of nanocellulose from three types of palm residues. J. Mater. Res. Technol. 10, 526-537.

Melikoğlu, A. Y., Bilek, S. E., and Cesur, S. (2019). Optimum alkaline treatment parameters for the extraction of cellulose and production of cellulose nanocrystals from apple pomace. Carbohydr. Polym. 215, 330-337.

Meng, F., Wang, G., Du, X., Wang, Z., Xu, S., and Zhang, Y. (2019). Extraction and characterization of cellulose nanofibers and nanocrystals from liquefied banana pseudo-stem residue. Compos. Part B Eng. 160, 341-347. doi: 10.1016/j. compositesb.2018.08.048

Mishra, R. K., Sabu, A., and Tiwari, S. K. (2018). Materials chemistry and the futurist eco-friendly applications of nanocellulose: status and prospect. J. Saudi Chem. Soc. 22, 949-978. doi: 10.1016/j.jscs.2018.02.005

Missoum, K., Sadocco, P., Causio, J., Belgacem, M. N., and Bras, J. (2014). Antibacterial activity and biodegradability assessment of chemically grafted nanofibrillated cellulose. Mater. Sci. Eng. C 45, 477-483. doi: 10.1016/j.msec. 2014.09.037

Modenbach, A. A., and Nokes, S. E. (2014). Effects of sodium hydroxide pretreatment on structural components of biomass. Trans. ASABE 57, 11871198. doi: $10.13031 /$ trans.57.10046

Mondragon, G., Fernandes, S., Retegi, A., Peña, C., Algar, I., Eceiza, A., et al. (2014). A common strategy to extracting cellulose nanoentities from different plants. Ind. Crops Prod. 55, 140-148.

Moniruzzaman, M., and Ono, T. (2013). Separation and characterization of cellulose fibers from cypress wood treated with ionic liquid prior to laccase treatment. Bioresour. Technol. 127, 132-137. doi: 10.1016/j.biortech.2012. 09.113

Moon, R. J., Martini, A., Nairn, J., Simonsen, J., and Youngblood, J. (2011). Cellulose nanomaterials review: structure, properties and nanocomposites. Chem. Soc. Rev. 40:3941. doi: 10.1039/c0cs00108b 
Morais, J. P. S., Rosa, M. D. F., de Souza Filho, M. D. S. M., Nascimento, L. D., do Nascimento, D. M., and Cassales, A. R. (2013). Extraction and characterization of nanocellulose structures from raw cotton linter. Carbohydr. Polym. 91, 229-235. doi: 10.1016/j.carbpol.2012.08.010

Naduparambath, S., Jinitha, T. V., Shaniba, V., Sreejith, M. P., Balan, A. K., and Purushothaman, E. (2018). Isolation and characterisation of cellulose nanocrystals from sago seed shells. Carbohydr. Polym. 180, 13-20. doi: 10.1016/ j.carbpol.2017.09.088

Naduparambath, S., and Purushothaman, E. (2016). Sago seed shell: determination of the composition and isolation of microcrystalline cellulose. (MCC). Cellulose 23, 1803-1812. doi: 10.1007/s10570-016-0904-3

Nascimento, D. M., Almeida, J. S., Dias, A. F., Figueirêdo, M. C. B., Morais, J. P. S., Feitosa, J. P., et al. (2014). A novel green approach for the preparation of cellulose nanowhiskers from white coir. Carbohydr. Polym. 110, 456-463.

Nascimento, P., Marim, R., Carvalho, G., and Mali, S. (2016). Nanocellulose produced from rice hulls and its effect on the properties of biodegradable starch films. Mater. Res. 19, 167-174. doi: 10.1590/1980-5373-mr-2015-0423

Nascimento, S. A., and Rezende, C. A. (2018). Combined approaches to obtain cellulose nanocrystals, nanofibrils and fermentable sugars from elephant grass. Carbohydr. Polym. 180, 38-45.

Ng, H.-M., Sin, L. T., Tee, T.-T., Bee, S.-T., Hui, D., Low, C.-Y., et al. (2015). Extraction of cellulose nanocrystals from plant sources for application as reinforcing agent in polymers. Compos. Part B Eng. 75, 176-200.

Oliveira, F. B. D., Bras, J., Pimenta, M. T. B., Curvelo, A. A. D. S., and Belgacem, M. N. (2016). Production of cellulose nanocrystals from sugarcane bagasse fibers and pith. Ind. Crops Prod. 93, 48-57. doi: 10.1016/j.indcrop.2016.04.064

Ooi, S. Y., Ahmad, I., and Amin, M. C. I. M. (2016). Cellulose nanocrystals extracted from rice husks as a reinforcing material in gelatin hydrogels for use in controlled drug delivery systems. Ind. Crops Prod. 93, 227-234. doi: 10.1016/j.indcrop.2015.11.082

Ovalle-Serrano, S. A., Gómez, F. N., Blanco-Tirado, C., and Combariza, M. Y. (2018). Isolation and characterization of cellulose nanofibrils from Colombian Fique decortication by-products. Carbohydr. Polym. 189, 169-177. doi: 10.1016/ j.carbpol.2018.02.031

Panaitescu, D. M., Frone, A. N., and Nicolae, C. (2013). Micro- and nanomechanical characterization of polyamide 11 and its composites containing cellulose nanofibers. Eur. Polym. J. 49, 3857-3866. doi: 10.1016/j.eurpolymj. 2013.09.031

Peng, B. L., Dhar, N., Liu, H. L., and Tam, K. C. (2011). Chemistry and applications of nanocrystalline cellulose and its derivatives: a nanotechnology perspective. Can. J. Chem. Eng. 89, 1191-1206. doi: 10.1002/cjce.20554

Phanthong, P., Ma, Y., Guan, G., and Abudula, A. (2015). Extraction of nanocellulose from raw apple stem. J. Jpn. Inst. Energy 94, 787-793. doi: 10. 3775/jie.94.787

Phanthong, P., Reubroycharoen, P., Hao, X., Xu, G., Abudula, A., and Guan, G. (2018). Nanocellulose: extraction and application. Carbon Resour. Convers. 1, 32-43. doi: 10.1016/j.crcon.2018.05.004

Picheth, G. F., Luiz, C. P., Maria, R. S., Marco, A. W., Novak, C. S., Martin, A. A., et al. (2017). Bacterial cellulose in biomedical applications: a review. Int. J. Biol. Macromol. 104, 97-106. doi: 10.1016/j.ijbiomac.2017.05.171

Ramesh, S., and Radhakrishnan, P. (2019). Cellulose nanoparticles from agroindustrial waste for the development of active packaging. Appl. Surf. Sci. 484, 1274-1281. doi: 10.1016/j.apsusc.2019.04.003

Rampazzo, R., Alkan, D., Gazzotti, S., Ortenzi, M. A., Piva, G., and Piergiovanni, L. (2017). Cellulose nanocrystals from lignocellulosic raw materials, for oxygen barrier coatings on food packaging films. Packag. Technol. Sci. 30, 645-661. doi: $10.1002 /$ pts. 2308

Rangan, A., Manchiganti, M. V., Thilaividankan, R. M., Kestur, S. G., and Menon, R. (2017). Novel method for the preparation of lignin-rich nanoparticles from lignocellulosic fibers. Ind. Crops Prod. 103, 152-160.

Rathore, A., and Pradhan, M. K. (2017). Hybrid cellulose bionanocomposites from banana and jute fibre: a review of preparation, properties and applications. Mater. Today Proc. 4, 3942-3951. doi: 10.1016/j.matpr.2017.02.294

Rebouillat, S., and Pla, F. (2013). State of the art manufacturing and engineering of nanocellulose: a review of available data and industrial applications. J. Biomater. Nanobiotechnol. 04, 165-188. doi: 10.4236/jbnb.2013.42022

Rezende, C. A., de Lima, M. A., Maziero, P., deAzevedo, E. R., Garcia, W., and Polikarpov, I. (2011). Chemical and morphological characterization of sugarcane bagasse submitted to a delignification process for enhanced enzymatic digestibility. Biotechnol. Biofuels 4, 54-54. doi: 10.1186/1754-68344-54

Robles, E., Fernandez-Rodriguez, J., Barbosa, A. M., Gordobil, O., Carreno, N. L., and Labidi, J. (2018). Production of cellulose nanoparticles from blue agave waste treated with environmentally friendly processes. Carbohydr. Polym. 183, 294-302.

Rosa, M. F., Medeiros, E. S., Malmonge, J. A., Wood, D. F., Glenn, G., Orts, W. J., et al. (2010). Cellulose nanowhiskers from coconut husk fibers: effect of preparation conditions on their thermal and morphological behavior. Carbohydr. Polym. 81, 83-92. doi: 10.1016/j.carbpol.2010.01.059

Salama, A., Etri, S., Mohamed, S. A. A., and El-Sakhawy, M. (2018). Carboxymethyl cellulose prepared from mesquite tree: new source for promising nanocomposite materials. Carbohydr. Polym. 189, 138-144. doi: 10. 1016/j.carbpol.2018.02.016

Salehpour, S., Jonoobi, M., Ahmadzadeh, M., Siracusa, V., Rafieian, F., and Oksman, K. (2018). Biodegradation and ecotoxicological impact of cellulose nanocomposites in municipal solid waste composting. Int. J. Biol. Macromol. 111, 264-270. doi: 10.1016/j.ijbiomac.2018.01.027

Santos, R. M. D., Flauzino Neto, W. P., Silvério, H. A., Martins, D. F., Dantas, N. O., and Pasquini, D. (2013). Cellulose nanocrystals from pineapple leaf, a new approach for the reuse of this agro-waste. Ind. Crops Prod. 50, 707-714. doi: 10.1016/j.indcrop.2013.08.049

Sharma, A., Thakur, M., Bhattacharya, M., Mandal, T., and Goswami, S. (2019). Commercial application of cellulose nano-composites - a review. Biotechnol. Rep. 21:e00316. doi: 10.1016/j.btre.2019.e00316

Sheikhi, A. (2019). Emerging Cellulose-Based Nanomaterials and Nanocomposites. Amsterdam: Elsevier doi: 10.1016/b978-0-12-814615-6.00009-6

Sheltami, R. M., Abdullah, I., Ahmad, I., Dufresne, A., and Kargarzadeh, H. (2012). Extraction of cellulose nanocrystals from mengkuang leaves. (Pandanus tectorius). Carbohydr. Polym. 88, 772-779. doi: 10.1016/j.carbpol.2012. 01.062

Shesan, J. O., Stephen, C. A., Chioma, G. A., Neerish, R., and Rotimi, E. S. (2019). "Improving the mechanical properties of natural fiber composites for structural and biomedical applications," in Renewable and Sustainable Composites, eds A. B. Pereira and F. A. O. Fernandes (London: IntechOpen), doi: 10.5772/ intechopen. 85252

Shesan, J. O., Stephen, J. A., Chioma, G. A., Neerish, R., and Rotimi, E. S. (2019a). "fiber-matrix relationship for composites preparation," in Renewable and Sustainable Composites, eds B. P. António and F. A. O. Fernandes (London: IntechOpen).

Shesan, J. O., Stephen, J. A., Chioma, G. A., Neerish, R., and Rotimi, E. S. (2019b). "improving the mechanical properties of natural fiber composites for structural and biomedical applications," in Renewable and Sustainable Composites, eds B. P. António and F. A. O. Fernandes (London: IntechOpen).

Singh, V., Joshi, S., and Malviya, T. (2018). Carboxymethyl cellulose-rosin gum hybrid nanoparticles: an efficient drug carrier. Int. J. Biol. Macromol. 112, 390-398. doi: 10.1016/j.ijbiomac.2018.01.184

Šturcová, A., Davies, G. R., and Eichhorn, S. J. (2005). Elastic modulus and stress-transfer properties of tunicate cellulose whiskers. Biomacromolecules 6 , 1055-1061. doi: 10.1021/bm049291k

Taha, M., Foda, M., Shahsavari, E., Aburto-Medina, A., Adetutu, E., and Ball, A. (2016). Commercial feasibility of lignocellulose biodegradation: possibilities and challenges. Curr. Opin. Biotechnol. 38, 190-197. doi: 10.1016/j.copbio.2016. 02.012

Tee, T. T., Lee, T. S., Gobinatgh, R., Bee, S. T., Hui, D., Kong, I., et al. (2013). Investigation of nano-size montmorillonite on enhancing polyvinyl alcoholstarch blends prepared via solution cast approach. Compos. Part B Eng. 47, 238-247. doi: 10.1016/j.compositesb.2012.10.033

Teixeira, E. D. M., Bondancia, T. J., Teodoro, K. B. R., Corrêa, A. C., Marconcini, J. M., and Mattoso, L. H. C. (2011). Sugarcane bagasse whiskers: extraction and characterizations. Ind. Crops Prod. 33, 63-66. doi: 10.1016/j.indcrop.2010.08. 009

Thielemans, W., Warbey, C. R., and Walsh, D. A. (2009). Permselective nanostructured membranes based on cellulose nanowhiskers. Green Chem. 11:531. doi: 10.1039/b818056c

Torgbo, S., and Sukyai, P. (2019). Fabrication of microporous bacterial cellulose embedded with magnetite and hydroxyapatite nanocomposite scaffold for 
bone tissue engineering. Mater. Chem. Phys. 237:121868. doi: 10.1016/j. matchemphys.2019.121868

Trilokesh, C., and Uppuluri, K. B. (2019). Isolation and characterization of cellulose nanocrystals from jackfruit peel. Sci. Rep. 9, 16709-16709. doi: 10.1038/s41598019-53412-x

Varanasi, S., Low, Z.-X., and Batchelor, W. (2015). Cellulose nanofibre composite membranes - biodegradable and recyclable UF membranes. Chem. Eng. J. 265, 138-146. doi: 10.1016/j.cej.2014.11.085

Wang, X., Wang, S., Liu, W., Wang, S., Zhang, L., Sang, R., et al. (2019). Facile fabrication of cellulose composite films with excellent UV resistance and antibacterial activity. Carbohydr. Polym. 225:115213. doi: 10.1016/j.carbpol. 2019.115213

Wijaya, C. J., Saputra, S. N., Felycia, E. S., Putro, J. N., Alfin, K., Ju, Y. H., et al. (2017). Cellulose nanocrystals from passion fruit peels waste as antibiotic drug carrier. Carbohydr. Polym. 175, 370-376. doi: 10.1016/j.carbpol.2017. 08.004

Xu, X., Liu, F., Jiang, L., Zhu, J. Y., Haagenson, D., and Wiesenborn, D. P. (2013). Cellulose nanocrystals vs. cellulose nanofibrils: a comparative study on their microstructures and effects as polymer reinforcing agents. ACS Appl. Mater Interfaces. 5, 2999-3009. doi: 10.1021/am302624t

Zhang, K., Sun, P., Liu, H., Shang, S., Song, J., and Wang, D. (2016). Extraction and comparison of carboxylated cellulose nanocrystals from bleached sugarcane bagasse pulp using two different oxidation methods. Carbohydr. Polym. 138, 237-243.

Conflict of Interest: The authors declare that the research was conducted in the absence of any commercial or financial relationships that could be construed as a potential conflict of interest.

Copyright (c) 2021 Owonubi, Agwuncha, Malima, Shombe, Makhatha and Revaprasadu. This is an open-access article distributed under the terms of the Creative Commons Attribution License (CC BY). The use, distribution or reproduction in other forums is permitted, provided the original author(s) and the copyright owner(s) are credited and that the original publication in this journal is cited, in accordance with accepted academic practice. No use, distribution or reproduction is permitted which does not comply with these terms. 